\title{
EFECTOS DE LOS SUBTÍTULOS INTRALINGÜÍSTICOS Y LOS SUBTÍTULOS BILINGÜES AUMENTADOS SOBRE EL APRENDIZAJE INCIDENTAL DE VOCABULARIO EN ESPAÑOL COMO LENGUA EXTRANJERA
}

\section{EFFECTS OF GLOSSED CAPTIONS AND BILINGUAL SUBTITLES ON THE INCIDENTAL VOCABULARY LEARNING OF SPANISH LEARNERS}

\author{
Bianca González Ortega \\ UNIBA-Universtitat de Barcelona \\ bianca.eei@gmail.com \\ Iban Mañas Navarrete \\ Universitat de Barcelona \\ iban.manas@ub.edu
}

\begin{abstract}
RESUMEN
Las investigaciones sobre aprendizaje incidental de vocabulario han demostrado que es posible aprender unidades léxicas a partir del visionado de input audiovisual. Además, existen evidencias de que diversas formas de subtítulos incrementan este aprendizaje. Algunos nuevos tipos de subtitulado han mostrado mayores ganancias léxicas que las modalidades tradicionales. Destacan entre estos los subtítulos intralingüísticos aumentados, o con glosas, y los subtítulos bilingües, puesto que ambos facilitan el acceso al significado. Sin embargo, no se ha determinado cuál de estos tipos de subtítulos genera mayor aprendizaje de vocabulario cuando ambos cuentan con glosas. El presente estudio investiga los efectos de los subtítulos intralingüísticos y bilingües aumentados sobre el aprendizaje incidental de vocabulario receptivo mediante el visionado de input audiovisual por parte de aprendientes de español como lengua segunda o lengua extranjera (EL2/LE) en contexto de no inmersión. Se trata de un estudio cuasiexperimental con un diseño pretest-posttest en el que participaron 82 estudiantes, de una universidad estadounidense de diversas facultades, de nivel intermedio-bajo en español (American Council on the Teaching of Foreign Languages [ACTFL]). Aunque las ganancias léxicas fueron pequeñas, los resultados indican que ambos tipos de subtítulos pueden favorecer el aprendizaje de vocabulario a nivel de la asociación entre forma y significado. Los resultados no registraron diferencias significativas en los efectos de los dos tipos de subtítulos. Si bien la mayoría de los participantes usó las glosas disponibles en las pistas escritas, no se evidenció que esto incidiera en los beneficios obtenidos del tratamiento. Se observaron distintos patrones de aprendizaje de los ítems según su frecuencia léxica, siendo la banda de frecuencia léxica media la que recoge mayores ganancias.
\end{abstract}

\begin{abstract}
Research on incidental learning of vocabulary has shown that it is possible to learn lexical items by viewing audiovisual input. Additionally, there is evidence that various forms of subtitles increase this learning. Some new types of subtitling have been shown to produce greater lexical gains than traditional modalities. Among these are glossed captions and bilingual subtitles, as both facilitate access to meaning. However, it has not been determined which of these subtitles generates more vocabulary learning when both include glosses. This study investigates the effects of glossed captions and glossed bilingual subtitles on the incidental learning of receptive vocabulary through audiovisual input. The quasiexperimental design included 82 intermediate-low level Spanish learners from an American university in a non-immersion context. Although learning gains were low, the results indicate that both types of subtitles promote vocabulary learning at the level of the association between form and meaning. The results did not show significant differences in the effects of the two types of subtitles. While most of the participants used the glosses available on the written text, no evidence was found that this affected the benefits obtained from the treatment. Different learning patterns of the items were observed according to their lexical frequency. Both treatments produced the highest vocabulary gains in the midfrequency band.
\end{abstract}

Palabras clave: aprendizaje incidental de vocabulario, input audiovisual, subtítulos intralingüísticos, subtítulos bilingües, subtítulos duales, subtítulos aumentados, glosas
Keywords: incidental vocabulary learning, audiovisual input, captions, bilingual subtitles, dual subtitles, glossed captions, glossed subtitles, glosses. 


\section{INTTRODUCCIÓN}

Desde los años 80, se ha considerado que el material audiovisual es una fuente de input contextualizado y redundante que podría contribuir a la adquisición de lenguas segundas y extranjeras (L2/LE), dependiendoen gran medida de las limitaciones que la complejidad de la lengua en uso y la velocidad del habla supongan para la comprensión (Vanderplank, 2016). Por ello, se han investigado los efectos de los subtítulos que acompañan los vídeos sobre el aprendizaje, evidenciando los beneficios de estas pistas escritas para la comprensión, el procesamiento ascendente -bottom upde la lengua y el aprendizaje de vocabulario (Montero Pérez y Rodgers, 2019).

La televisión digital ofrece nuevas formas de subtitulado (Mitterer y McQueen, 2009) e impacta la manera en que se aprenden y se enseñan lenguas (Muñoz-Basols, 2019). Concretamente, los subtítulos bilingües -audio en L2 y pistas escritas en L1 y L2- y los intralingüísticos -audio y pistas escritas en L2- con glosas brindan acceso al significado de las unidades léxicas, por lo que su potencial para el aprendizaje de vocabulario ha generado gran interés. Sin embargo, hasta donde hemos podido encontrar, no se han comparado los efectos de estos subtítulos cuando ambos cuentan con glosas. En este estudio se investigan los efectos de los subtítulos intralingüísticos aumentados y los subtítulos bilingües aumentados sobre el aprendizaje incidental de vocabulario, es decir aprendizaje no intencional, por parte de estudiantes de español como lengua extranjera (ELE) de nivel intermedio-bajo ${ }^{1}$ en contexto de no inmersión. Más aún, nos proponemos indagar en el papel de las glosas sobre las posibles ganancias léxicas y explorar si el acceso al significado mitiga la influencia de los conocimientos previos en este aprendizaje. Asimismo, la presente investigación supone una contribución empírica a la bibliografía existente en el ámbito del español como L2/LE, lengua que se encuentra infrarrepresentada en el conjunto de estudios de esta especialidad en comparación con otras como el inglés.

1 Todos los estudiantes estaban inscritos en la segunda asignatura de español de nivel intermedio que se ofrece en la institución, equivalente al nivel intermedio-bajo (intermediate low) del American Council on the Teaching of Foreign Languages (ACTFL, 2012) o A2 de acuerdo al Marco Común Europeo de Referencia (MCER) (Consejo de Europa, 2001). Para saber más sobre las equivalencias entre ambos sistemas de niveles, consultar Martínez Baztán (2008). 


\section{APRENDIZAJE Y DESARROLLO DE VOCABULARIO EN SEGUNDAS IENGUAS}

A pesar de la diversidad de planteamientos teóricos que explican el funcionamiento del aprendizaje de vocabulario (Agustín Llach, 2011; Chacón-Beltrán et al., 2010; Pavičić, 2008), se ha identificado de manera transversal en todos ellos una serie de factores que influyen en este tipo de aprendizaje, entre los que se encuentran la naturaleza incremental de la adquisición léxica y, consecuentemente, la importancia de los encuentros múltiples y contextualizados con las unidades léxicas, esto es, la necesidad de exposición al input (Pavičić, 2008). La exposición al input y el uso de la lengua con fines extralingüísticos pueden generar ganancias léxicas o aprendizaje incidental de vocabulario (Schmitt, 2010a). En contraste, hablamos de aprendizaje intencional de vocabulario cuando se realizan actividades orientadas a aprender unidades léxicas explícitamente (Schmitt, 2008). Las ganancias obtenidas de manera incidental son relativamente pequeñas (Webb, 2016) y ocurren, en su mayoría, a nivel receptivo (Webb, 2019); por este motivo, su valor reside en proporcionar una vía para reciclar las palabras que se han aprendido explícitamente, familiarizarse con nuevas unidades léxicas, obtener información sobre el contexto en que estas ocurren y, al mismo tiempo, mejorar las destrezas comunicativas (Schmitt, 2010b).

En cuanto al potencial de la exposición a material audiovisual auténtico para el aprendizaje incidental de vocabulario, se ha demostrado que ver televisión es tan efectivo como la exposición a textos escritos y que la combinación de imágenes e input auditivo que ofrecen los programas de $\mathbf{T V}$ podría facilitar el aprendizaje léxico más que la lectura (Webb y Rodgers, 2009). Además, esta combinación resulta más comprensible que el input exclusivamente auditivo, dado que las imágenes habitualmente complementan el significado de las unidades léxicas (Webb y Rodgers, 2009, p. 355).

Otro factor relevante al valorar los efectos de las modalidades de input sobre el vocabulario es la exposición que los aprendientes reciben fuera del aula. Tanto niños (Lindgren y Muñoz, 2013) como adultos (Peters, 2018) suelen preferir el visionado de material audiovisual en la L2/LE, percibiéndolo como una actividad agradable y provechosa para su aprendizaje (Pujadas y Muñoz, 2017, en Pujadas y Muñoz, 2019). 
Por otro lado, existe un requerimiento de cobertura léxica² para la comprensión del input audiovisual (Pujadas y Muñoz, 2020) y no todos los aprendientes tienen el vocabulario necesario para obtener tal cobertura (Montero Pérez, 2019). Igualmente, se ha comprobado que el aprendizaje incidental de palabras a partir de la exposición a input audiovisual tiende a seguir la máxima del efecto Matthew que postula que los ricos se hacen más ricos (Neuman y Koskinen, 1992, p. 103), es decir, que las personas con un mayor tamaño de vocabulario tienden a aprender más palabras (Montero et al., 2014; Peters \& Webb, 2018; Peters, 2019; Suárez y Gesa, 2019), lo que sugiere que los conocimientos léxicos previos afectan su potencial aprendizaje incidental (Webb, 2016, p. 130; Webb y Rodgers, 2009, p. 342). Esto podría deberse a que existe una correlación positiva entre el tamaño de vocabulario y la comprensión del input audiovisual (Montero et al., 2014; Pujadas y Muñoz, 2020) y una mayor comprensión permite prestar más atención a las unidades léxicas desconocidas (Webb y Chang, 2015, p. 671). Estos hallazgos están en consonancia con lo observado en relación con el input escrito (por ejemplo, en Horst et al., 1998), aunque se piensa que el tamaño de vocabulario requerido en el caso del input audiovisual sería menor, ya que las imágenes podrían facilitar la comprensión (Chapel y Curtis, 2000, p. 421). Por todo ello, podría ser útil brindar opciones de ayuda para la comprensión del input audiovisual (Montero Pérez, 2019).

\subsection{INPUT AUDIOTISUAL SUBTITUL ADO}

Una de esas ayudas para la comprensión del material audiovisual son los subtítulos. Estas pistas escritas proporcionan acceso a muestras de lengua que de otra forma serían incomprensibles y facilitan la adquisición de la L2/LE, como se ha comprobado desde la investigación en materiales multimedia, comprensión oral, teoría de la codificación dual y adquisición léxica (Vanderplank, 2016). Respecto a esto último, se han estudiado los efectos de distintas formas de subtitulado sobre el aprendizaje de vocabulario, incluyendo el uso de múltiples subtítulos al mismo tiempo -subtítulos

\footnotetext{
${ }^{2}$ La cobertura léxica es el porcentaje de palabras conocidas en un texto (Webb, 2010a, p. 498). Si bien este porcentaje no es igual al porcentaje de comprensión, es un elemento fundamental para que tal entendimiento sea posible (Webb \& Rodgers, 2009, p.339). Como se verá más adelante, uno de los posibles beneficios de algunos tipos de subtítulos es aumentar este porcentaje.
} 
duales- y el acceso a explicaciones en la L2 o traducciones a la L1 -subtítulos aumentados- (Talaván Zanón, 2011).

Los subtítulos bilingües aparecen en la bibliografía sobre aprendizaje de L2/LE a principios del siglo XXI. Chang (2003) acuña el término subtítulos duales (dual subtitling) y estudia su efecto sobre la comprensión de materiales audiovisuales, concluyendo que estos subtítulos contribuyen a la comprensión del imput incluso más que los interlingüísticos y los intralingüísticos. En cuanto a sus efectos sobre la adquisición léxica, las pistas simultáneas en la L1 y la L2 podrían ofrecer tanto los beneficios de los subtítulos intralingüísticos, esto es, la asociación de la forma escrita y la forma fonológica de las unidades léxicas (García, 2017; Lazareva y Loerts, 2017), como las ventajas de los interlingüísticos, en concreto, mayor comprensión del contenido. No obstante, aún hoy los subtítulos duales son poco comunes (García 2017, p.471) y los estudios sobre sus efectos en el aprendizaje de vocabulario son escasos (Li, 2016).

En el ámbito de la educación, desde principios del siglo XXI se han investigado distintas maneras de optimizar la utilidad de los subtítulos, entre ellas la expansión de la información que estos proporcionan, incorporando, por ejemplo, definiciones que los transforman en un recurso interpretativo - translational resource- en aras de permitir al aprendiente aproximarse a palabras desconocidas por medio de otras más familiares (Anderson-Inman et al., 2009, pp. 21-24). En el campo de la enseñanza y aprendizaje de L2/LE un antecedente similar lo constituyen las glosas multimedia en textos escritos, cuyos beneficios incluyen la facilitación de la comprensión, la minimización de las inferencias erróneas y de las interrupciones generadas por el uso del diccionario y la adecuación a las preferencias del aprendiente, favoreciendo la adquisición léxica inclusive más que las glosas tradicionales (Mohsen y Balakumar, 2011) que, por su parte, ya han mostrado tener efectos positivos en la misma al reducir el tamaño de vocabulario requerido para la comprensión de un texto (Nation, 2001), aumentar la atención que se presta a las palabras del input (Nation, 2001; Schmitt, 2008) y facilitar su reconocimiento formal y semántico a corto plazo (Hidalgo, 2020). 
Los subtítulos aumentados podrían considerarse recursos para el aprendizaje incidental con glosas léxicas -incidental learning with lexical glosses- en el marco de los estudios de Aprendizaje de Vocabulario Asistido por Ordenador, según la categorización propuesta por Ma (2013). Al combinar diccionarios electrónicos y subtítulos, también constituirían herramientas de asistencia para la comprensión, de acuerdo al Help facilities framework de Pujolà (2002). Estas dos características concuerdan con la apreciación de Webb (2010b) en cuanto al potencial del uso de glosas para aumentar la cobertura léxica del input audiovisual, incorporación que, según el autor, favorecería tanto la comprensión del contenido como el aprendizaje incidental de vocabulario. De manera similar, Montero Pérez et al. (2018) afirman que este tipo de anotación facilitaría la asociación entre forma y significado y concuerdan con Cokely y Muñoz (2019) en que, así, las glosas reducirían la dependencia de los procesos de inferencia. Todo ello sugiere que los subtítulos aumentados podrían facilitar el aprovechamiento del input audiovisual por parte de aprendientes que de otra forma no tendrían el tamaño de vocabulario necesario para la comprensión aún más que los subtítulos tradicionales.

\section{ESTUDIOS DE INPUT AUDIOVISUAL EN EL APRENDIZAJE DE $\mathrm{L} 2 / \mathrm{LE}$}

En relación con la adquisición léxica, Li (2016) y Lazareva y Loerts (2017) han encontrado que los subtítulos bilingües generan mayores ganancias a nivel receptivo que los monolingües. Además, Raine (2012) y García (2017) han investigado las percepciones de los usuarios respecto a la utilidad de los subtítulos duales para el aprendizaje de vocabulario, comprobando que este tipo de ayuda en el input es una de las opciones preferidas a tal fin. Asimismo, se han descartado algunas preocupaciones respecto al exceso de información escrita que podrían representar las pistas simultáneas L1/L2, pues las evidencias sugieren que no existen diferencias significativas en la carga cognitiva que generan los subtítulos bilingües y los monolingües (Liao, Kruger y Doherty, 2020), ni en el procesamiento visual de los vídeos con algunas de estas formas de subtitulado o sin subtítulos incluso en usuarios sin conocimientos previos en la L2/LE (Lazareva y Loerts, 2017). En consonancia con esto, se ha observado que los 
aprendientes de nivel preintermedio consideran más fácil leer subtítulos bilingües que intralinguísticos (Raine, 2012) y que muchos usuarios prefieren escuchar los vídeos en la L2/LE y leerlos igualmente en la L2, cambiando a la pista en la L1 al oír palabras desconocidas (García, 2017).

Algunos estudios, por su parte, no han encontrado que los subtítulos bilingües tengan efectos positivos en el aprendizaje de vocabulario. Por ejemplo, en una investigación con estudiantes universitarios, Wang (2019) evaluó la recuperación del significado de unidades léxicas a partir de la exposición a distintas condiciones de subtitulado (L1, L2, bilingües o sin subtítulos) y obtuvo resultados diferentes para grupos de distintos años de pregrado y postgrado e inclusive entre dos grupos del mismo año. Sin embargo, dado que no quedan claras las diferencias en los niveles de competencia lingüística de los participantes y que en uno de los grupos se descartó gran cantidad de ítems debido a los conocimientos previos de los estudiantes, no se pueden sacar conclusiones definitivas.

En el caso de los subtítulos aumentados, los resultados experimentales parecen confirmar su potencial para el aprendizaje de vocabulario. De hecho, se ha comparado su efectividad a la de otros tipos de subtítulos, obteniendo mejores resultados que los interlingüísticos (Sakunkoo y Sakunkoo, 2009), intralingüísticos (Aldera y Mohsen, 2013; Hsu, 2018; Montero Pérez et al., 2018), bilingües (Kovacs y Miller, 2014), e incluso que aquellos con realce de las formas léxicas (Hsieh, 2019), especialmente a nivel de la asociación entre forma y significado.

En el ámbito de la didáctica de lenguas, la primera investigación sobre el tema la conducen Aldera y Mohsen (2013). Las anotaciones ${ }^{3}$ en este estudio incluían una definición en la L2, un ejemplo de uso del ítem léxico y una imagen ilustrativa de su significado, para las quince palabras clave que se evaluarían tras el tratamiento. A fin de determinar si tales anotaciones afectarían el aprendizaje de vocabulario, 50 estudiantes de inglés (nivel A2; L1: árabe), divididos en tres grupos, vieron un vídeo animado bajo las siguientes condiciones: animación con subtítulos intralingüísticos y

\footnotetext{
${ }^{3}$ En la bibliografía sobre el tema, se suele utilizar los términos glosa y anotación de manera intercambiable (Mohsen \& Balakumar, 2011).
} 
anotaciones de palabras clave, animación con subtítulos intralingüísticos sin anotaciones y la animación sola. Los grupos expuestos a subtítulos obtuvieron mayores ganancias léxicas (reconocimiento de la forma y recuperación del significado) que el grupo que solo vio la animación, siendo superior el desempeño de la sección con anotaciones.

Al igual que Aldera y Mohsen (2013), Hsu (2018), Montero Pérez et al. (2018) y Hsieh (2019) investigan los efectos de las anotaciones de palabras clave en la adquisición léxica. Hsu (2018), se centra en el aprendizaje de vocabulario de inglés para los negocios por parte de 50 estudiantes universitarios sinohablantes. El input (tres vídeos de 15 minutos tomados de una serie de telerrealidad sobre negocios) incluía subtítulos intralingüísticos completos en los que un recuadro alrededor de cada unidad target indicaba la disponibilidad de una traducción a la L1 y una definición en la L2, anotando así un total de ocho palabras por vídeo. De este modo, Hsu (2018) comparó los efectos a corto (inmediatamente después del tratamiento) y largo plazo (tres semanas después) de distintas modalidades de visionado (sin subtítulos, subtítulos intralingüísticos y subtítulos intralingüísticos con glosas) sobre el aprendizaje de vocabulario receptivo y productivo. La modalidad con glosas generó mayor aprendizaje que las otras dos modalidades tanto a corto como a largo plazo. Más aún, las ganancias léxicas generadas por los subtítulos con glosas no mostraron diferencias significativas en el tiempo.

Por su parte, Montero Pérez et al. (2018) condujeron el estudio más extenso en el tema a la fecha. Los autores investigaron el aprendizaje incidental e intencional de vocabulario por parte de 227 estudiantes universitarios holandeses, aprendientes de francés (nivel intermedio e intermedio-alto), en cuatro condiciones de subtitulado: sin subtítulos, subtítulos intralingüísticos completos, subtítulos bimodales resumidos (solo palabras clave) y subtítulos bimodales resumidos con glosas en la L1. Todos los grupos con subtítulos mostraron un desempeño significativamente mejor que el grupo control a nivel del reconocimiento de la forma y no se observaron diferencias significativas entre el uso de subtítulos intralingüísticos completos y el de subtítulos bimodales resumidos, es decir, los usuarios de subtítulos completos prestaron atención a las 
palabras desconocidas sin necesidad de que estuviesen destacadas. Además, los grupos con acceso a glosas obtuvieron resultados significativamente mejores que aquellos sin subtítulos y con subtítulos intralingüísticos completos, lo cual sugiere que las glosas de palabras clave mejoran la atención a las unidades léxicas. Sin embargo, las diferencias entre los grupos con subtítulos bimodales resumidos con y sin glosas no fueron significativas en el reconocimiento de la forma, lo cual se explica por el hecho de que ambas condiciones presentaban el mismo formato de visualización de las formas léxicas (Montero Pérez, 2018, pp. 18-19). En relación con el aprendizaje del significado, los participantes con acceso a glosas obtuvieron las puntuaciones más altas tanto en el reconocimiento como en la recuperación del mismo. Además, el análisis del comportamiento de los participantes evidenció que la consulta de las glosas se correlaciona positivamente con el aprendizaje de vocabulario, lo cual sugiere que el acceso al significado por medio de glosas en la L1 favorece la asociación inicial entre forma y significado. Asimismo, el tamaño del vocabulario de los participantes mostró relación con sus ganancias léxicas (a mayor vocabulario, más aprendizaje en todas las dimensiones) y su uso de las glosas (a mayor vocabulario, menos consultas), lo que podría vincularse a la noción de cobertura léxica.

Estos efectos positivos de los subtítulos con glosas sobre el aprendizaje inicial de vocabulario se confirman en el estudio de Hsieh (2019). El autor comparó la incidencia sobre el aprendizaje de vocabulario de cinco condiciones de visionado de dos vídeos (cada uno de entre cuatro y cinco minutos y visto dos veces): sin subtítulos, subtítulos intralingüísticos con y sin audio, subtítulos intralingüísticos con realce de las unidades target y subtítulos intralingüísticos con realce y glosas (L1) en las unidades target. Al igual que en el estudio anterior, los subtítulos con glosas generaron resultados significativamente mejores en el reconocimiento y la recuperación del significado. Estos subtítulos también generaron mejores resultados a nivel de reconocimiento de la forma, seguidos por aquellos con realce de las unidades target. Asimismo, se observó que la modalidad con realce de las unidades target favoreció el reconocimiento de la forma, pero no el del significado y se verificó que los subtítulos intralingüísticos con 
audio generan mayores ganancias léxicas que aquellos sin audio y que la ausencia de subtítulos.

Por su parte, Teng (2020) investigó los efectos de los subtítulos con glosas sobre el aprendizaje de vocabulario de 240 estudiantes de primaria (L1: chino; L2: inglés; nivel intermedio). Concretamente, comparó los efectos de las glosas a nivel de la forma, el significado y el uso de 20 unidades léxicas a partir de la exposición a subtítulos completos y resumidos con y sin glosas. Además, probó cada condición con organizadores gráficos -advanced organizers - de la información antes del tratamiento y sin ellos. Si bien los subtítulos completos con glosas en combinación con organizadores gráficos arrojaron los mejores resultados, este tipo de subtítulos también produjo las mayores ganancias léxicas entre las condiciones sin tareas previas al visionado. A la luz de los estudios presentados se observa que los subtítulos con glosas ofrecen resultados prometedores tanto en su versión de palabras clave como en la no resumida.

Las investigaciones de los efectos de los subtítulos duales y aumentados sobre el aprendizaje de vocabulario en L2/LE son, como hemos visto, relevantes y fructíferas, pero escasas en el ámbito del EL2/LE. Hasta el momento, se ha encontrado que también en esta lengua los subtítulos intralingüísticos generan mayor aprendizaje léxico que los interlingüísticos (Stewart y Pertusa, 2004) y que la ausencia de subtítulos (Cintrón-Valentín et al., 2019), aunque en algunos casos estas ganancias pueden ser pequeñas (Stewart y Pertusa, 2004) o no ser significativas (Cassell, 2018). Asimismo, se han observado efectos positivos del realce de la formas léxicas (Cintrón-Valentín et al., 2019) y de la repetición del visionado del material audiovisual con subtítulos intralingüísticos en el primer visionado o en ambos (Winke et al., 2010), lo que podría relacionarse con el papel de la atención en la adquisición de vocabulario.

Como se ha mostrado, los tipos de subtítulos ofrecidos por los avances tecnológicos de los últimos treinta años evidencian gran potencial para el aprendizaje de L2/LE. En el caso del aprendizaje de vocabulario, tanto los subtítulos bilingües como los subtítulos con glosas parecen generar mayores ganancias léxicas que otras formas de subtitulado. Sin embargo, hace falta más investigación, en particular en 
español. El estudio que se presenta a continuación pretende contribuir en esta dirección.

El objetivo principal del estudio es determinar qué efecto produce el tipo de subtítulos que acompaña al material audiovisual en el aprendizaje incidental de vocabulario por parte de estudiantes de EL2/LE universitarios de nivel intermediobajo en contexto de no inmersión. Para alcanzar dicho objetivo se han formulado las siguientes de preguntas de investigación:

1. ¿Qué efectos generan los subtítulos intralingüísticos aumentados y los subtítulos bilingües aumentados, a corto y largo plazo, sobre el aprendizaje incidental de vocabulario de estudiantes universitarios de EL2/LE de nivel intermedio-bajo en contexto de no inmersión?

A pesar de que se ha demostrado que los conocimientos léxicos previos afectan al potencial aprendizaje incidental del vocabulario (Webb, 2016; Webb y Rodgers, 2009), especialmente en el sentido de que, cuantas más palabras conoce el aprendiente, más vocabulario adquiere del visionado de vídeos en la L2/LE (Neuman y Koskinen, 1992; Montero Pérez et al., 2014; Peters et al., 2016; Peters, 2019; Puimège y Peters, 2019), los resultados que demuestran esta relación son menos consistentes que los referentes al input escrito (Peters, 2019). En vista de lo anterior, y considerando que tanto los subtítulos bilingües como los intralingüísticos aumentados podrían aumentar la cobertura léxica, merece la pena comprobar si tal relación se observa con estos tipos de subtitulado. Así, nuestro segundo objetivo de investigación consiste en examinar la relación de los conocimientos previos en EL2/LE y el aprendizaje incidental de vocabulario mediante el visionado de material audiovisual con subtítulos aumentados. Para explorar esta cuestión, formulamos la siguiente pregunta de investigación:

2. ¿Qué relación se establece entre los conocimientos léxicos previos en la L2/LE y las ganancias léxicas obtenidas del visionado de material audiovisual con subtítulos aumentados a corto y largo plazo?

Por medio de esta pregunta podremos constatar si en el aprendizaje incidental de vocabulario mediante el uso de subtítulos aumentados también se observa el llamado 
efecto Matthew (Neuman y Koskinen, 1992) o si el aumento de la cobertura léxica permite que los aprendientes con menores conocimientos léxicos previos en la L2/LE se beneficien tanto como aquellos más avanzados. A la fecha, el único estudio -hasta donde tenemos conocimiento- con subtítulos aumentados (específicamente, subtítulos bimodales resumidos con glosas) que ha explorado la relación entre el tamaño de vocabulario y el aprendizaje léxico es el de Montero Pérez et al. (2018) y tal como con otros tipos de subtítulos se encontró una relación positiva en este sentido. Aunque los subtítulos aumentados en nuestro estudio tienen otras características (intralingüísticos completos y bilingües en lugar de bimodales resumidos), nuestra hipótesis es que también los aprendientes con mayor tamaño de vocabulario obtendrán mayores ganancias léxicas.

Otra cuestión relevante para comprender los efectos de los conocimientos previos en el aprendizaje incidental de vocabulario es la naturaleza incremental de este tipo de aprendizaje (Pavičić, 2008). Ya que es posible conocer parcialmente un ítem léxico (Barcroft, 2015; Agustín Llach, 2011) y que la frecuencia de las palabras en el corpus de una lengua suele considerarse un buen indicador de su familiaridad para los hablantes, las palabras más frecuentes tienden a aprenderse más fácilmente que aquellas que son inusuales (Puimège y Peters, 2019). En vista de que es posible que los aprendientes hayan encontrado previamente algunas de las palabras presentes en el input y que ese conocimiento parcial contribuya a que asimilen esos ítems más fácilmente, nos proponemos indagar en las posibles relaciones entre la frecuencia léxica de las unidades target y su aprendizaje mediante la siguiente pregunta de investigación:

3. ¿Qué efectos produce la frecuencia de las unidades léxicas sobre las ganancias léxicas obtenidas del visionado de material audiovisual con subtítulos aumentados a corto y largo plazo?

Por otro lado, cabe examinar si al disponer de subtítulos bilingües aumentados los aprendientes consultan las glosas y si los efectos de este tipo de subtitulado sobre el aprendizaje léxico difieren de los generados por los subtítulos intralingüísticos aumentados. Así, nos planteamos la siguiente pregunta de investigación: 
4. ¿Qué incidencia tiene en términos de ganancias léxicas el uso de glosas durante el visionado de material audiovisual con subtítulos intralingüísticos aumentados y subtítulos bilingües aumentados en el aprendizaje incidental de vocabulario?

Considerando que los participantes de estudios previos con subtítulos interactivos han favorecido las traducciones de las unidades léxicas individuales aun al tener acceso a traducciones a nivel de la oración (Kovacs y Miller, 2014) y que se ha observado que los aprendientes de L2/LE prestan atención a las palabras desconocidas en los subtítulos (Montero Pérez et al., 2018; Montero Pérez, 2019), nuestra hipótesis es que los estudiantes expuestos a subtítulos bilingües aumentados consultarán las glosas, aunque probablemente en menor medida que aquellos expuestos a subtítulos intralingüísticos aumentados, ya que podrán recurrir a las pistas en la L1 para aclarar dudas, tal como reporta García (2017). Además, examinaremos si los conocimientos léxicos previos influyen de alguna manera en la decisión del aprendiente de usar las glosas, y si el uso de las mismas implica diferencias en el aprendizaje de vocabulario, tal como reportan Montero Pérez et al. (2018).

En suma, con este objetivo exploramos otros factores que podrían afectar el aprendizaje incidental de vocabulario a partir de la exposición a input audiovisual, tales como los conocimientos previos de los aprendientes en la L2/LE y las características de los ítems en términos de frecuencia léxica.

Los objetivos y preguntas de investigación planteados están dirigidos a definir los efectos de los subtítulos aumentados, intralingüísticos y bilingües, en el aprendizaje léxico incidental por parte de estudiantes de ELE de nivel intermedio-bajo, contribuyendo así a comprender los beneficios y limitaciones de estas ayudas ofrecidas por las nuevas tecnologías para el aprendizaje de lenguas no nativas.

\section{METODOLOGÍA}

\subsection{PARTICIPANTES}

En el estudio participaron 104 estudiantes (72 mujeres y 32 hombres) de grado de distintas especialidades de una universidad pública estadounidense. Se incluyeron finalmente en el análisis las respuestas de 82 participantes, tras el filtrado de datos 
perdidos. Para conocer el perfil sociolingüístico de los participantes, los estudiantes completaron una versión reducida del cuestionario LEAP (Language Experience and Proficiency Questionnaire), desarrollado y estandarizado para bilingües inglés-español por Marian et al. (2007). En la tabla 1 se recoge un resumen de la información obtenida por el cuestionario. En cuanto al nivel de competencia lingüística en EL2/LE, todos los estudiantes estaban inscritos en la asignatura de español de nivel intermedio, equivalente al nivel intermedio-bajo del ACTFL (American Council on the Teaching of Foreign Languages) o al nivel A2 de acuerdo al MCER (Marco Común Europeo de Referencia).

Respecto al nivel de competencia, se recogió la respuesta numérica (en una escala Likert de diez puntos) de cada participante según su nivel autorreportado para la destreza de producción oral. De acuerdo con Marian et al. (2007), este indicador es el mejor predictor de la competencia lingüística general en una L2/LE. En nuestro estudio, el grupo expuesto a subtítulos intralingüísticos aumentados declaró tener unas habilidades de producción oral adecuadas, mientras que el grupo expuesto a subtítulos bilingües aumentados valoró sus habilidades como ligeramente por encima de lo adecuado. No obstante, la diferencia entre estas medias no resulta significativa $(t=$ $1.9688, g l=62, p>0.05)$.

\begin{tabular}{|c|c|c|c|c|c|c|}
\hline Grupo & Sexo & $\begin{array}{l}\text { Edad media } \\
(\text { mín-máx) }\end{array}$ & $\begin{array}{l}\text { Lengua } \\
\text { materna }\end{array}$ & $\begin{array}{l}\text { AoL } \\
(M)\end{array}$ & $\begin{array}{l}\text { Competencia en } \\
\text { español } \\
\text { autorreportado } \\
\text { (máx.:10) }\end{array}$ & $\begin{array}{l}\text { Conocimiento } \\
\text { léxico en } \\
\text { español } \\
\text { (TEVI-R) } \\
\text { (máx.: 54) }\end{array}$ \\
\hline Biling & $\begin{array}{l}\text { M: } 28 \\
\text { H: } 14\end{array}$ & $\begin{array}{c}19.94 \\
(17-29)\end{array}$ & Inglés & 10.44 & 6.00 & $\begin{array}{l}23.93 \\
(5.00)\end{array}$ \\
\hline Intraling & $\begin{array}{l}\text { M: } 28 \\
\text { H: } 12\end{array}$ & $\begin{array}{c}20.03 \\
(18-29)\end{array}$ & Inglés & 10.33 & 5.13 & $\begin{array}{l}23.20 \\
(5.07)\end{array}$ \\
\hline
\end{tabular}

Intraling: subtítulos intralingüísticos aumentados; biling: subtítulos bilingües aumentados; AOL (del inglés Age of Initial Learning): edad de inicio del aprendizaje de la L2/LE.

TABLA 1. Perfil de los participantes y conocimiento léxico por grupos

Puesto que en este tipo de estudio es conveniente utilizar una medida general de vocabulario para controlar las diferencias individuales entre los participantes (Peters et al., 2016, p. 146), se suministró además una adaptación del test de vocabulario en imágenes TEVI-R (Echeverría et al., 2005). Concretamente, se trata de una prueba de 
reconocimiento del significado en la que el examinador proporciona la forma oral de las unidades léxicas y el examinado debe seleccionar la imagen correspondiente entre cuatro opciones. Esta prueba, en principio diseñado para determinar si el tamaño del vocabulario receptivo de los hablantes nativos del español se adecúa a su edad, sigue una estructura similar al Peabody Test (Echeverría et al., 2005, p. 7) que, a pesar de obedecer al mismo objetivo para el inglés, se ha utilizado en estudios con hablantes no nativos (por ejemplo, Marian et al., 2007). En los estudios con hablantes de L2/LE los resultados no se relacionan con las bandas etarias correspondientes a los nativos, sino que se toman como indicador para verificar la homogeneidad de la muestra.

El test de contraste de medias entre los dos grupos, con la corrección de Welch, no halló diferencias significativas $(t=0.650, g l=79.786, p>0.1)$. A partir de estos resultados podemos asumir que ambos grupos son equivalentes en cuanto a su competencia lingüística y su conocimiento de vocabulario.

\subsection{Materiales y procedimiento}

Debido a las limitaciones en el tiempo de acceso a los participantes, nuestro diseño mide únicamente una dimensión del aprendizaje léxico, incidiendo en la cantidad de unidades conocidas en esa dimensión y no en la profundidad de dicho conocimiento. Además, no todas las dimensiones de este conocimiento se desarrollan a la vez y, por tanto, debe considerarse qué tipo de aprendizaje es más probable en el contexto que se evalúa y elegir el formato correspondiente (Nation y Chung, 2011). En el caso del aprendizaje de vocabulario a partir de actividades de comprensión de input centrado en el significado, Nation y Chung (2011) recomiendan las medidas pasivas ${ }^{4}$ de los modelos de evaluación del vocabulario de Laufer y Goldstein (2004).

En este trabajo se ha seleccionado el test de reconocimiento pasivo del significado de Laufer y Goldstein (2004), que mide la asociación más débil o inicial entre la forma

\footnotetext{
4 Autores como Read (2019) utilizan los términos reconocimiento y recuperación para referirse a las pruebas pasivas (o de conocimiento receptivo) y activas (o de conocimiento productivo) respectivamente. En el presente usamos estos términos de manera intercambiable, entendiendo que en las pruebas de reconocimiento o de conocimiento receptivo generalmente se utilizan ítems de selección múltiple, mientras que en las pruebas de recuperación o de conocimiento productivo los participantes deben escribir su respuesta (Read, 2019, p. 547). Para una discusión respecto a los supuestos de cada denominación, ver Read (2019) y Laufer y Goldstein (2004).
} 
y el significado de un ítem léxico y consiste en proporcionar la unidad target como estímulo y que el participante elija su significado de entre cuatro opciones en la L1. Siguiendo este formato, se creó un test que evalúa las 25 unidades target seleccionadas, verificando que todas las opciones de respuesta pertenecieran a la misma categoría gramatical. Además, se contó con la colaboración de una especialista en lingüística hispánica hablante nativa de inglés para comprobar que la traducción correcta correspondiera al sentido de la palabra en el input del tratamiento. Se añadieron 35 distractores a fin de evitar un efecto de prueba que pudiera alertar a los participantes de las unidades que serían evaluadas después del tratamiento (Nation y Webb, 2011, en Kremmel, 2019). Estos distractores se eligieron según su frecuencia léxica para compensar la falta de homogeneidad en la distribución de las unidades target en los distintos rangos de frecuencia (propia del carácter auténtico del input). Así, se obtuvo un diseño inicial de la prueba de 60 ítems en tres rangos de frecuencia léxica según el ranking del Corpus del Español (Davies, 2019): entre 0 y 4000 (cinco unidades target en posiciones entre 3000 y 4000 y nueve distractores más frecuentes), entre 4001 y 10000 (12 unidades target y tres distractores) y, por último, unidades en posiciones posteriores a 10001 (ocho unidades target y 22 distractores).

Tras un pilotaje en dos fases con estudiantes de características similares $(n=27)$ a las de los participantes de nuestro estudio, se determinó que el grado de dificultad del test era muy alto, por lo que se incluyeron unidades target de mayor frecuencia léxica a fin de tener un instrumento más sensible al aprendizaje que pudiera ocurrir en aprendientes de este nivel de competencia en la L2. La prueba final $(k=60)$ consta de 35 unidades target (ver Anexo) y 25 distractores divididos en tres franjas diferentes según su frecuencia léxica. En concreto, las unidades target se distribuyen como muestra la tabla 2. 


\begin{tabular}{cccc}
\hline & $\begin{array}{c}\mathbf{0}-\mathbf{4 0 0 0} \\
\text { alta }\end{array}$ & $\begin{array}{c}4001-10000 \\
\text { media }\end{array}$ & $\begin{array}{c}>10001 \\
\text { baja }\end{array}$ \\
\hline Sustantivos & 9 & 9 & 3 \\
\hline Verbos & 4 & 2 & 1 \\
\hline Adjetivos & 1 & 2 & 3 \\
\hline Adverbios & 0 & 0 & 1 \\
\hline TABLA 2. Distribución de las unidades léxicas target según categoría gramatical y rango de frecuencia
\end{tabular}

Esta prueba también se utilizó para examinar las ganancias léxicas a partir de los distintos tipos de subtitulado, si bien se descartaron los ocho distractores en los que cada grupo obtuvo menores puntuaciones a fin de evitar la fatiga de los participantes. Así, en la prueba posterior al tratamiento (posttest), se redujo la cantidad de distractores de 22 a 14, para un total de 49 ítems. No se eliminaron todos los distractores para disminuir las probabilidades de un efecto de prueba en la evaluación a largo plazo (delayed posttest). Esta prueba tardía, idéntica al posttest, se incorporó con el objetivo de evaluar los efectos a largo plazo de cada tipo de subtitulado. El tiempo transcurrido entre el posttest y el delayed posttest fue de dos semanas.

Visto que nuestro estudio se centra en el aprendizaje incidental de vocabulario y que este puede ser entendido como el aprendizaje léxico que ocurre como producto de una actividad centrada en el significado (Webb, 2019) ${ }^{5}$, se decidió incorporar algunas preguntas de comprensión y advertir a los participantes al respecto antes del visionado. Solo se incluyeron tres preguntas de selección simple, de modo que fuese posible aplicar el instrumento en el tiempo disponible y que no se generara un efecto de fatiga en los participantes. Además, considerando que los aprendientes de lengua suelen ignorar las ayudas disponibles en los materiales ALAO (Pujolà, 2002, p. 240) y que una de nuestras preguntas explora la relación entre el uso de las glosas y el aprendizaje de vocabulario, se incluyó una pregunta cerrada respecto a la consulta de

\footnotetext{
5 Webb (2019, p. 226) destaca que ni la inclusión de glosas, ni el realce del texto, el contexto de aprendizaje (en el aula o en casa) o la disponibilidad de diccionarios para facilitar la comprensión afectan esa definición.
} 
las mismas ${ }^{6}$. Nuevamente, se comprobó la adecuación del instrumento a través de un pilotaje.

Sobre la elección del material audiovisual, se seleccionó un fragmento de 11'22” de un capítulo de una serie de televisión en español. Dos docentes de la asignatura de español valoraron el material como adecuado en cuanto a contenido y nivel de dificultad. En cuanto al soporte de subtitulación, se usó la extensión Language Learning with Netflix (LLN), un programa de libre acceso para Google Chrome que brinda distintas opciones de subtitulado y enlaza las palabras de las pistas escritas a diccionarios en línea. La primera configuración elegida fue la de subtítulos intralingüísticos aumentados, es decir, aquellos en los que tanto el audio como la pista escrita están en español y se puede acceder a traducciones en la L1 al pulsar sobre cualquiera de las palabras de los diálogos (Figura 1). La segunda configuración utilizada fue la de subtítulos bilingües aumentados. Al igual que en la opción anterior, el audio está en español, pero bajo los subtítulos en esta lengua se muestra la pista escrita en la L1. Igualmente, se puede acceder a glosas en la L1 al pulsar sobre las palabras en la L2/LE (Figura 2).

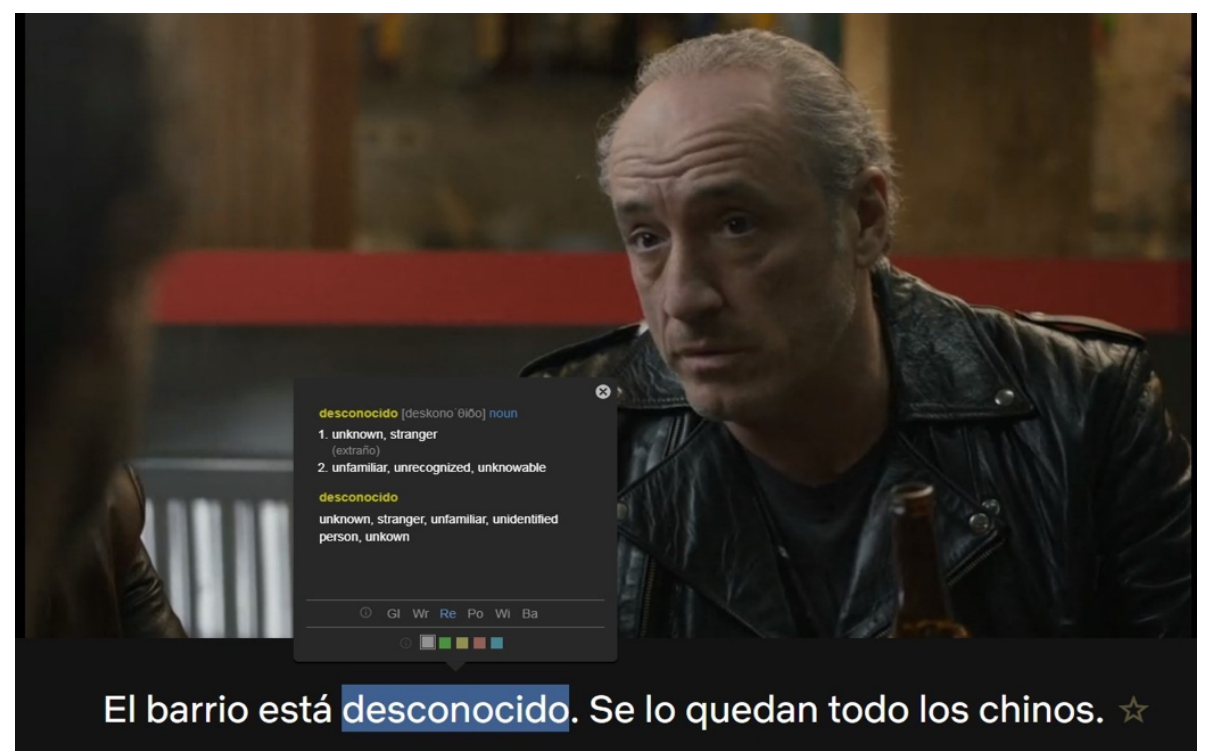

Figura 1. Subtítulos intralingǘsticos aumentados

\footnotetext{
${ }^{6}$ Aunque un estudio exhaustivo de esta relación requeriría de una tecnología que permitiera registrar los patrones de consulta de glosas por parte de los participantes (tal como la utilizada por Montero Pérez et al., 2018), nos decantamos por un autorreporte general debido a las limitaciones de recursos.
} 


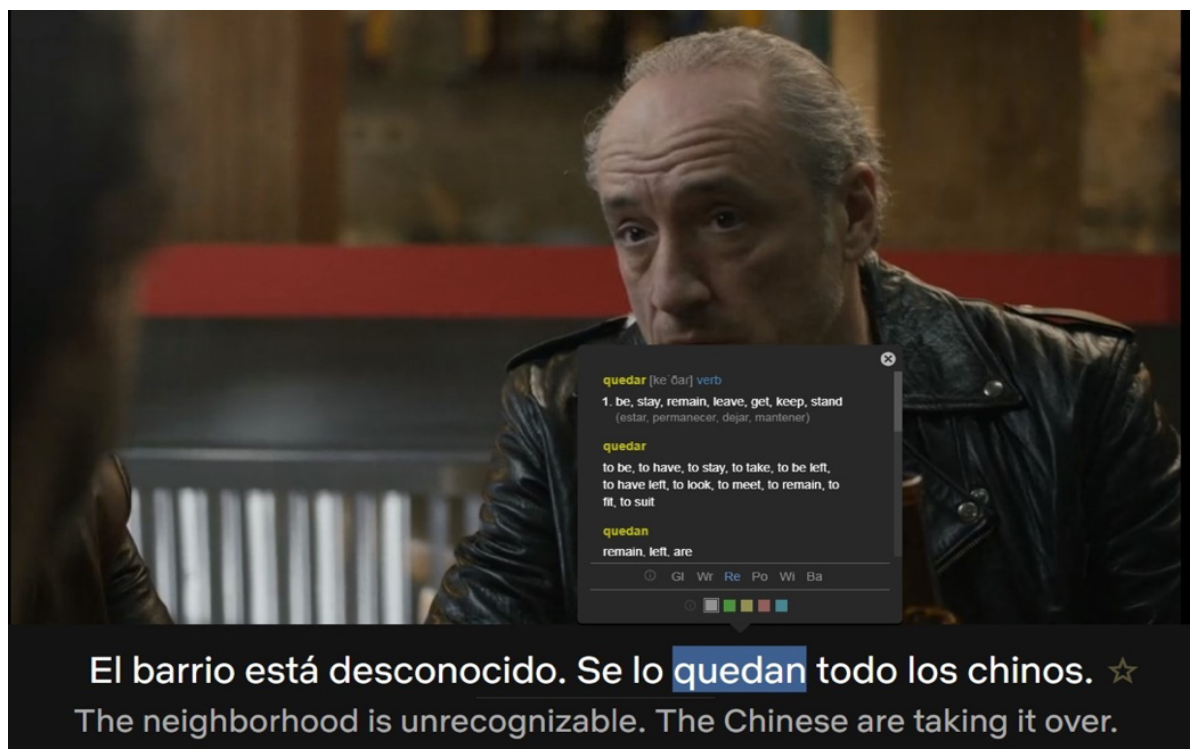

FIGURA 2. Subtítulos bilingües aumentados

Los datos se recogieron en cuatro sesiones. Durante la primera sesión se presentó el proyecto sin especificar el objetivo del estudio. Asimismo, se administraron el consentimiento de participación voluntaria, el cuestionario de características individuales y la prueba general de vocabulario. La lectura de los estímulos de esta última la realizó el docente de la clase.

En la segunda sesión se aplicó la prueba previa al tratamiento o pretest y se les pidió llevar sus computadoras portátiles ${ }^{7}$ (con Google Chrome instalado) y audífonos a la siguiente sesión. Dos semanas después tuvo lugar la tercera sesión. Se indicó a los participantes que debían ver hasta el minuto 12 del episodio seleccionado y se les informó que habría preguntas de comprensión al respecto. No se comunicó que habría una prueba de vocabulario. En ese contexto, se les explicó cómo acceder a las glosas cuando requirieran de ayuda para la comprensión. Tras unos 15 minutos, se verificó que todos los participantes hubiesen terminado el visionado y se brindó acceso al cuestionario. Finalmente, se les pidió completar el posttest. Dos semanas más tarde, se repitió esta misma prueba.

\footnotetext{
${ }^{7}$ De acuerdo a Webb (2010b, p. 215), el uso de glosarios se ajusta a la naturaleza del visionado de televisión centrado en el significado siempre que los aprendientes puedan pausar los programas y hacer las consultas de manera individual cuando sea necesario. El uso de computadoras portátiles nos ha permitido garantizar tal condición.
} 
La realización de todas las pruebas se llevó a cabo a través del sitio web Survey Monkey, manteniendo la redacción en inglés a fin de maximizar la comprensión y evitar un efecto de agotamiento en los participantes. En las tres pruebas del vocabulario del tratamiento (pretest, posttest y delayed posttest) se presentaron los ítems de forma aleatoria y distinta para cada participante por medio de la configuración correspondiente en Survey Monkey. De esta manera se procuró disminuir las probabilidades de un efecto de prueba.

\subsection{ANÁLisis}

Las respuestas de todas las pruebas se codificaron según un criterio de precisión, esto es, otorgando un punto por cada respuesta correcta y cero puntos por cada respuesta incorrecta.

Se descartaron los participantes que solo hubiesen realizado una de las tres pruebas del vocabulario target. Al aplicar esta condición, la muestra se redujo a 82 participantes. Posteriormente, se realizó la identificación y el recuento de los datos perdidos para comprobar el supuesto de aleatoriedad que quedó confirmado mediante el test de Little $\left(\chi^{2}=25.261, g l=6, p=0.117\right)$. A continuación se imputaron los valores perdidos mediante la función pmm (predictive mean matching), que sigue una imputación por regresión que permite predecir los valores perdidos a partir de las observaciones disponibles por participante. A partir de este conjunto de respuestas se computaron los niveles de precisión en porcentajes, sobre los que realizaron los pertinentes análisis.

Debido principalmente al diseño no balanceado del estudio, se optó por ajustar un modelo lineal de efectos mixtos sobre la variable respuesta. En la construcción del modelo se comprobó el aporte de los tres factores del estudio sobre el porcentaje de acierto aplicando la prueba de razón de verosilimitud (Likelihood-ratio test). Como factores de efectos fijos se incluyeron el tiempo (pretest, posttest y delayed posttest), los rangos de frecuencia léxica (alta, media y baja) y los grupos según tipo de subtítulos (intralingüísticos y bilingües). Se exploraron tanto los efectos simples como las interacciones. Además se identificó a cada participante en una variable independiente que se introdujo como efecto aleatorio en el modelo, lo que nos permite controlar la variabilidad debida a cada participante en la prueba. 
Las pruebas post hoc para explorar los efectos de interacciones se realizaron aplicando la corrección de Bonferroni sobre el nivel de significación.

Para el análisis sobre ganancias léxicas absolutas, se aplicó una serie de test de contraste de medias para muestras independientes entre los dos grupos. Si bien en estudios anteriores se ha considerado que las ganancias léxicas absolutas consisten en la diferencia entre las notas del prestest y las del posttest (Puimège y Peters, 2019, p. 431), solo hemos tomado esta medida como indicador de las ganancias a corto plazo. Teniendo en cuenta que los resultados del posttest indican la efectividad del tratamiento, pero solo los del delayed posttest deben considerarse como indicador de aprendizaje léxico (Schmitt, 2010a), calculamos también las ganancias léxicas absolutas a largo plazo, sustrayendo las notas del pretest a las del delayed posttest).

En cuanto al uso de glosas, se compararon las medias en la prueba de vocabulario general de los participantes que las consultaron y los que no lo hicieron a fin de explorar si la decisión de utilizar las anotaciones de los subtítulos influye en algún sentido sobre los conocimientos léxicos previos. Del mismo modo, se realizó una comparación de proporciones para determinar si la distribución de uso y rechazo de glosas es equivalente entre los grupos según el tipo de subtítulo.

Todos los datos se analizaron utilizando el entorno computacional $R$ (RStudio Team, 2015). Para la imputación de datos se empleó el paquete mice (Multivariate Imputation via Chained Equations) (van Buuren y Groothuis-Oudshoorn, 2011); para la creación del modelo de efectos mixtos se recurrió a la función lmer del paquete lme4 (Bates, Mächler, Bolker y Walker, 2015); la exploración de contrastes por pares se realizó con ayuda del paquete emmeans (Lenth, 2018).

\section{RESULTADOS}

A partir del conjunto de datos imputados obtenidos se calcularon los estadísticos descriptivos de cada grupo en los diferentes momentos de recogida de la prueba y según la frecuencia de palabra. En la tabla 4 se recogen las medias y desviaciones típicas para cada grupo según estas dos condiciones. 
Pre-test Post-test Delayed-test

\begin{tabular}{cccccccccc}
\cline { 3 - 10 } & alta & media & baja & alta & media & baja & alta & media & baja \\
\hline $\begin{array}{c}\text { Biling } \\
(\boldsymbol{n}=\mathbf{4 2})\end{array}$ & 39.63 & 33.52 & 26.79 & 50.00 & 52.93 & 34.82 & 48.98 & 48.35 & 32.44 \\
\hline Intraling & 43.75 & 38.46 & 28.75 & 52.50 & 51.92 & 36.56 & 48.57 & 50.96 & 31.56 \\
$(\boldsymbol{n}=\mathbf{4 0})$ & $(17.88)$ & $(17.16)$ & $(14.76)$ & $(17.61)$ & $(19.38)$ & $(15.08)$ & $(18.95)$ & $(19.91)$ & $(14.15)$ \\
\hline
\end{tabular}

TABLA 4. Estadísticos descriptivos sobre el índice de acierto (en porcentaje) por grupo en pre, post y delayed-post según frecuencia léxica

La Tabla 4 muestra que las medias y las desviaciones típicas de las puntuaciones logradas por cada grupo en los tres tiempos son cercanas entre sí, lo que sugiere un comportamiento bastante similar entre ellos. En todos los casos los valores de la desviación estándar son bastante próximos entre ambos grupos, lo que sugiere que los datos presentan una dispersión similar alrededor de la media en las tres pruebas realizadas. Aunque se observa que la desviación estándar se mantiene bastante homogénea en las tres pruebas para ambos grupos, el grupo expuesto a subtítulos bilingües aumentados es ligeramente más homogéneo que el grupo Intraling en sus respuestas a palabras de frecuencia alta y media. Respecto al tiempo, en la comparación entre pretest y posttest se confirma un incremento de precisión para todas las franjas de frecuencia en ambos grupos, y un decrecimiento entre el posttest y el delayed posttest. Las palabras de frecuencia más baja obtienen sistemáticamente en los dos grupos los índices de acierto más bajos. Estos resultados corroboran la adecuada selección de las unidades léxicas de la prueba.

A partir de estos datos se ajustó un primer modelo base en el que se incluyó el factor aleatorio de los participantes como único predictor. Este modelo tiene en cuenta únicamente la variabilidad atribuida a los participantes y su capacidad explicativa de la variabilidad de la variable respuesta. Los resultados mostraron que, de la varianza total en las respuestas obtenidas ( var $=358.10)$, la variabilidad asociada a los participantes del estudio entre sí (var $=84.13$ ) supone un $23.4 \%$ de la varianza explicada.

A este modelo se le incorporó la variable grupo, esto es, la distinción entre tipo de subtítulos. Su contribución al poder explicativo de la variable respuesta no resultó 
significativo en comparación con el modelo base $\left(\chi^{2}=0.53, g l=1, p=0.46\right)$, lo que sugiere que no hay diferencias en las respuestas de los participantes que se puedan atribuir al hecho de haber utilizado subtítulos intralingüísticos o bilingües. En cambio, tanto la frecuencia de palabra $\left(\chi^{2}=147.02, g l=2, p<0.01\right)$ como el tiempo de recogida de respuestas $\left(\chi^{2}=65.23, g l=2, p<0.01\right)$ sí supusieron un incremento significativo de la varianza explicada por el modelo. Para explorar la influencia de la interacción entre estos dos predictores, comparamos la potencia de un modelo aditivo y un modelo no aditivo. La prueba de razón de verosimilitud señaló que el modelo no aditivo supone un incremento significativo de la variabilidad explicada de las respuestas $\chi^{2}=$ 12.71, $g l=4, p=0.012$ ), lo cual indica un efecto significativo de la interacción entre frecuencia y tiempo sobre la variable dependiente. En la tabla 5 se resumen los estimados de este modelo final, junto con el efecto de cada nivel del factor y los correspondientes intervalos de confianza.

\begin{tabular}{|c|c|c|c|c|}
\hline Efectos fijos & Estimados & $\begin{array}{c}\text { Error } \\
\text { Estándar }\end{array}$ & $t$ & $\begin{array}{c}\text { Intervalos de } \\
\text { confianza }\end{array}$ \\
\hline (Constante) & 48.780 & 1.857 & 26.264 & $45.13 ; 52.42$ \\
\hline posttest & 2.439 & 2.148 & 1.135 & $-1.77 ; 6.65$ \\
\hline pretest & -7.142 & 2.148 & -3.324 & $-11.36 ;-2.92$ \\
\hline frecuencia baja & -16.768 & 2.148 & -7.803 & $-20.98 ;-12.55$ \\
\hline frecuencia media & 0.844 & 2.148 & 0.393 & $-3.37 ; 5.06$ \\
\hline posttest: frecuencia baja & 1.219 & 3.038 & 0.401 & $-4.74 ; 7.18$ \\
\hline pretest: frecuencia baja & 2.874 & 3.038 & 0.946 & $-3.09 ; 8.83$ \\
\hline posttest: frecuencia media & 0.375 & 3.038 & 0.123 & $-5.58 ; 6.34$ \\
\hline pretest: frecuencia media & -6.553 & 3.038 & -2.156 & $-12.51 ;-0.58$ \\
\hline Efectos aleatorios & var & $S D$ & & \\
\hline participante & 93.54 & 9.672 & & \\
\hline residuo & 189.32 & 13.759 & & \\
\hline
\end{tabular}

Nota: los niveles de las variables introducidas como efectos fijos que no aparecen en la lista son los que el modelo toma como nivel de referencia para construir la Constante.

TABLA 5. Resumen del modelo lineal de efectos mixtos 
Respecto a los factores aleatorios, comprobamos que la variabilidad entre participantes en este modelo presenta una varianza de 93.54, que supone a su vez un 33\% de la varianza total de la variable dependiente $(v a r=282.32)$, una vez despejado el total de la varianza explicada por los factores fijos. Sobre estos, se detectan efectos significativos tanto para el tiempo como para la frecuencia de palabra. La interacción entre ambos factores parece concretarse en la franja de frecuencia media entre los diferentes niveles de la variable tiempo. Podemos realizar una primera aproximación visual a estos resultados en el gráfico 1. Exploramos a continuación los efectos de interacción a partir de las comparaciones múltiples por pares.

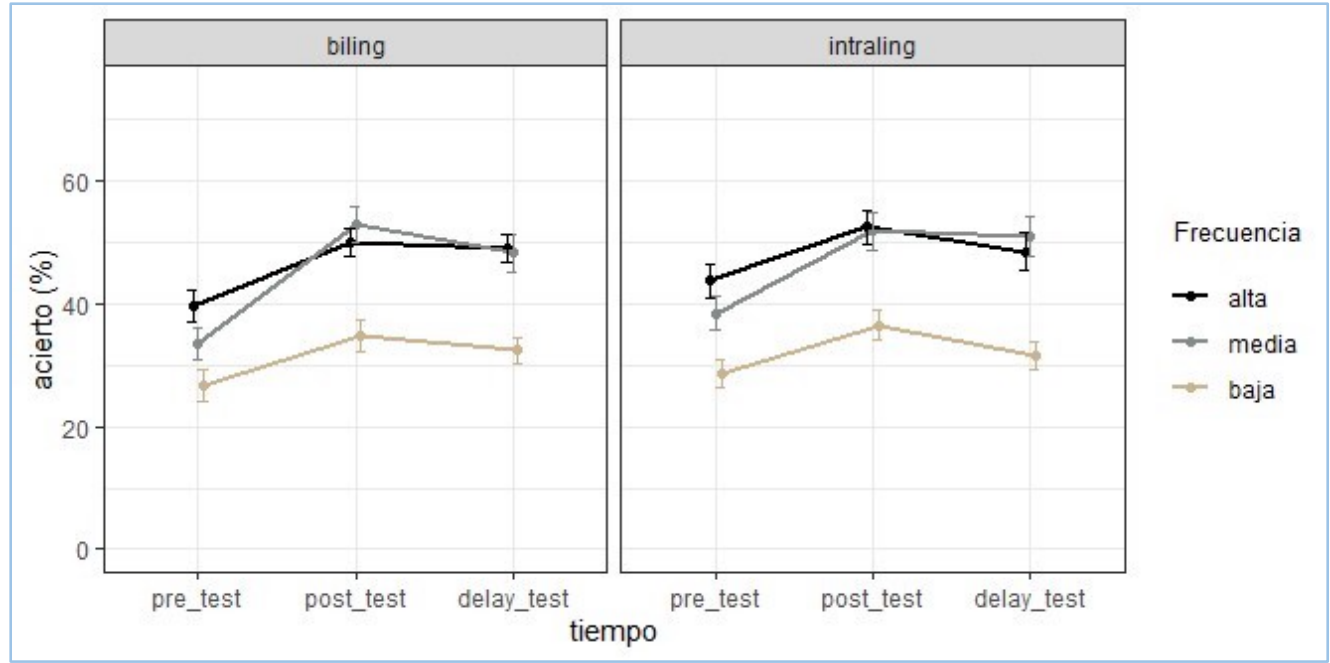

Gráfico 1. Interacción de frecuencia léxica y tiempo en los índices de acierto según el tipo de subtitulos

En el gráfico se observa la media y el error estándar de la media de los resultados logrados por los participantes para cada rango de frecuencia léxica en los tres tiempos. En general, los valores de ambos grupos son bastante similares. Comprobamos que hubo más aciertos en las bandas de frecuencia alta y media que en la de baja frecuencia, lo cual es consistente con la idea de que la frecuencia léxica es un buen indicador de su familiaridad para los hablantes (Puimège y Peters, 2019).

Los estimados del modelo señalan un incremento en el acierto de las palabras de la banda de frecuencia media en comparación con las de frecuencia alta $(\beta=0.84)$; un efecto que no resulta significativo pero que resulta contraintuitivo. Esto podría deberse a que las palabras desconocidas captan la atención de los aprendientes (Montero Pérez et al., 2018), pero, a la vez, los encuentros previos con las unidades facilitan su 
aprendizaje (Webb, 2010a). Es posible que los ítems de alta frecuencia léxica no llamaran la atención tanto como los de frecuencia media, por lo que el aprendizaje de estos últimos se habría visto favorecido. Las comparaciones por pares entre niveles de frecuencias en cada una de las tres pruebas confirmaron que las palabras de baja frecuencia recogen índices de acierto significativamente más bajos en los tres tiempos en comparación con las palabras de alta frecuencia $\left(t_{\text {pretest }}=-6.42, p<0.01 ; t_{\text {posttest }}=\right.$ $\left.7.19, p<0.01 ; t_{\text {delayed }}=-7.75, p<0.01\right)$ y con las de frecuencia media $\left(t_{\text {pretest }}=-3.78, p\right.$ $\left.<0.01 ; t_{\text {posttest }}=-7.75, p<0.01 ; t_{\text {delayed }}=-8.14, p<0.01\right)$. Por su parte, la comparación entre el nivel de acierto entre palabras de alta y media frecuencias no revela diferencias significativas a corto y largo plazo ( $\left.t_{\text {posttest }}=-0.56, p>0.5 ; t_{\text {delayed }}=-0.39, p>0.5\right)$, pero sí resultaron significativas en los resultados del pretest $(t=2.64, p=0.025)$. Todo esto permite afirmar que el aprendizaje de las unidades de alta y media frecuencia fue considerablemente mayor que el de las palabras de baja frecuencia léxica en ambos grupos.

Si analizamos la evolución del desempeño de los participantes a lo largo de las tres pruebas según el nivel de frecuencia de las palabras, puede apreciarse que las mayores diferencias se encuentran entre la prueba pretest y la prueba posttest para los tres tipos de palabras $\left(t_{\text {alta }}=4.43, p<0.01 ; t_{\text {media }}=-7.63, p<0.01 ; t_{\text {baja }}=3.66, p<0.01\right) . \mathrm{La}$ disminución de aciertos entre el posttest inmediato y a largo plazo no resulta significativa en ninguna franja de frecuencia $\left(t_{\text {alta }}=-1.12, p=0.77 ; t_{\text {media }}=-1.30, p=\right.$ 0.58 ; $t_{\text {baja }}=-1.69, p=0.27$ ). Esto que revela que no hubo una pérdida importante de las ganancias obtenidas en ninguno de los grupos de ítems. Más aún, la diferencia entre los resultados iniciales y los del delayed posttest también resulta significativa para las palabras de alta y media frecuencia $\left(t_{\text {alta }}=3.30, p<0.01 ; t_{\text {media }}=6.33, p<0.01\right)$, pero no así para las palabras de frecuencia baja $(t=1.97, p=0.14)$, de modo que es posible asumir que el aprendizaje de palabras de frecuencia alta y media a través de subtítulos se mantuvo tras dos semanas.

Si observamos las ganancias léxicas absolutas a corto plazo, calculadas a partir de la diferencia entre las notas del prestest y las del posttest, encontramos que las ganancias del grupo expuesto a subtítulos intralingüísticos aumentados $(M=10.28, D T=12.54)$ y 
las del grupo expuesto a subtítulos bilingües aumentados $(M=13.19, D T=11.72)$ no resultan significativamente distintas $(t=1.08, g l=80, p=0.280, d=0.2)$. Igualmente, se aprecia que las ganancias léxicas absolutas a largo plazo, calculadas a partir de la diferencia entre los resultados del pretest y los del delayed posttest, no resultan significativas $(t=1.09, g l=80, p=0.275, d=0.2$ ), aunque la ganancia del grupo de subtítulos bilingües $(M=10.47, D T=12.78)$ es más alta que la del grupo de subtítulos intralingüísticos $(M=7.21, D T=14.10)$. Estos resultados están en consonancia con los obtenidos en el ajuste del modelo de efectos mixtos.

Respecto al uso de las glosas, se registró un 61.84\% de los participantes que consultaron estas anotaciones, frente a un $38.16 \%$ no lo hizo. El análisis de comparación de proporciones confirmó que el uso de glosas varía en función del tipo de subtitulación al que pertenece el participante $\left(\chi^{2}=6.45, g l=1, p=0.01, V=0.2\right)$. Dentro del grupo expuesto a subtítulos intralingüísticos aumentados, el 75\% de los participantes utilizó las glosas, mientras que en el grupo expuesto a subtítulos bilingües aumentados solo lo hizo un $47.61 \%$ de los participantes. Se confirma, por tanto, que el uso de las glosas fue más recurrido en los participantes que solo tenían acceso a la pista en la L2. Asimismo, no se detectaron diferencias en los conocimientos léxicos previos de los participantes que hicieron uso de las glosas y los que no lo hicieron $(t=$ $-0.110, g l=50.814, p=0.912)$. Tampoco se encontraron diferencias significativas comparando las puntuaciones del posttest de los participantes agrupados en función del uso de glosas $(t=1.911, g l=59.528, p=0.2383)$. Estos resultados revelan que el uso de glosas no parece estar motivado por el nivel de conocimiento léxico previo ni tampoco incide en el aprendizaje léxico alcanzado durante el trabajo con material audiovisual.

Otro factor considerado a la hora de examinar los resultados del tratamiento fue el papel de los conocimientos previos. Concretamente, examinamos las correlaciones entre la prueba de vocabulario general y el posttest a partir del coeficiente de correlación de Pearson. Los resultados del mismo $(r=0.37, p=<0.001)$ confirman que existe una correlación positiva débil pero significativa entre los conocimientos léxicos previos y los resultados de la prueba posterior al tratamiento. Este tipo de correlación evidencia 
que a mayor tamaño de vocabulario, mejor índice de acierto ante la tarea de responder a los ítems del posttest (Puimège y Peters, 2019). No obstante, para concluir respecto a la influencia de estos conocimientos previos sobre el aprendizaje de nuevo vocabulario, analizamos también su relación con las ganancias léxicas absolutas.

Se inspeccionó la relación entre el desempeño en la prueba de vocabulario general y las ganancias absolutas a corto plazo. Los resultados $(r=0.06, p=0.53)$ muestran que no existe relación lineal entre estos dos indicadores. De manera similar, entre la prueba de vocabulario general y las ganancias léxicas absolutas a largo plazo tampoco se observa correlación $(r=0.1825, p=0.10)$. Consecuentemente, puede concluirse que no se detecta una relación entre los resultados de la prueba de vocabulario general y las ganancias léxicas absolutas ni a corto ni a largo plazo.

\section{DISCUSIÓN}

Los resultados obtenidos a partir del análisis de los datos confirman efectos equivalentes en el aprendizaje incidental del léxico entre el uso de subtítulos intralingüísticos y bilingües aumentados. En concreto, los resultados para las unidades de alta y media frecuencia fueron bastante similares, mientras que al compararlos con los resultados del rango de baja frecuencia léxica se aprecian diferencias significativas. Todo esto ratifica la incidencia del papel de la familiaridad con las palabras del input al que está expuesto el hablante no nativo.

Como se ha comentado, las ganancias léxicas obtenidas incidentalmente suelen ser pequeñas (Webb, 2016), en particular cuando se evalúan unidades de baja frecuencia léxica, puesto que estas suelen implicar una mayor carga de aprendizaje (Laufer, 2005; Montero Pérez et al., 2014; Nation, 2001, 2019). No obstante, los resultados de las ganancias léxicas a corto plazo en esta breve intervención (11'22'), que se traducen en 3.6 palabras en el grupo con subtítulos intralingüísticos y 4.6 en el grupo con subtítulos bilingües, evidencian un aprendizaje mayor que mediante la exposición a input audiovisual sin subtítulos. Por ejemplo, se ha visto que aprendientes de L2/LE de niveles entre B1 y B2 pueden obtener unas ganancias absolutas, en términos de reconocimiento del significado, de alrededor de 1.05 palabras tras la exposición a 30 minutos de televisión (Puimège y Peters, 2019). La mera incorporación de subtítulos 
en los contenidos audiovisuales, por lo tanto, ya supone un incremento del aprendizaje de léxico.

Por otro lado, la comparación con estudios que han usado subtítulos similares a los nuestros es menos directa, debido a diferencias en los diseños experimentales. En particular, los participantes expuestos a subtítulos bilingües en la investigación de Lazareva y Loerts (2017) reconocieron el significado de 14.31 unidades léxicas, pero esto tras realizar tres visionados de un vídeo de ocho minutos, así que deben considerarse los efectos positivos de la repetición del visionado sobre el aprendizaje léxico (Winke et al., 2010). En el estudio de Hsu (2018), los participantes expuestos a subtítulos intralingüísticos con glosas aprendieron alrededor de siete ítems. Sin embargo, solo las unidades target incluían glosas y su disponibilidad estaba indicada por un recuadro en torno a la palabra, por lo que pudo haber un efecto de realce. En la investigación de Montero Pérez et al. (2018), los participantes expuestos a subtítulos bimodales resumidos con glosas hicieron dos visionados del material audiovisual y acertaron alrededor de 13 ítems en el posttest de reconocimiento del significado. Visto que el diseño no incluía un pretest de esta dimensión del conocimiento léxico, no se pueden determinar sus ganancias absolutas. De manera similar, en el vídeo utilizado por Hsieh (2019) las unidades target estaban subrayadas y se proporcionaba el significado bajo las mismas, sin necesidad de pulsar sobre cada ítem. Además, también se realizaron dos visionados del material. Aunque la media en la prueba de reconocimiento del significado fue de 12.14 aciertos, no se pueden determinar las ganancias porque no hubo pretest. Finalmente, vemos que en el estudio de Li (2016) la media en el posttest del grupo con subtítulos bilingües fue de 7.94, pero tampoco hubo pretest.

Respecto a los resultados a largo plazo, nuestro estudio confirma parcialmente los hallazgos de Li (2016), quien observó mayor aprendizaje con subtítulos bilingües que con subtítulos monolingües (intra e interlingüísticos) y encontró que, aunque las medias disminuyeron a largo plazo $\left(M_{\text {post }}=7.94 ; M_{\text {delay }}=6.95\right)$, se mantuvo la ventaja del grupo expuesto a subtítulos bilingües sobre el grupo expuesto a subtítulos intralingüísticos. Sin embargo, los subtítulos en ese estudio no incluían glosas. En 
nuestra investigación, a pesar de que las medias de los dos grupos marcan esta tendencia, la diferencia entre los subtítulos bilingües y los intralingüísticos no resulta significativa.

En cuanto a los beneficios de los subtítulos intralingüísticos con glosas, observamos similitudes entre nuestros resultados y los de Aldera y Mohsen (2013). Estos autores encuentran que la media en la prueba de reconocimiento de vocabulario del grupo con subtítulos intralingüísticos aumentados disminuyó ligeramente del posttest al delayed posttest, pero continuó siendo superior a la del prettest. Ahora bien, en ese caso las anotaciones incluían definiciones, ejemplos en la L2 e imágenes, y la mitad de la prueba también consistió en el reconocimiento del significado por medio de imágenes. Además, solo las unidades target incluían anotaciones y estaban destacadas en otro color.

En definitiva, buena parte de los estudios anteriores no ha incluido pruebas previas al tratamiento, por lo que no se pueden comparar las ganancias léxicas. En los que ha habido pretest (Aldera y Mohsen, 2013), las ganancias han sido de alrededor de 8.65 ítems a corto plazo y 6.30 a largo plazo, pero con otros tipos de glosas, limitadas a las unidades target, y con cierto tipo de realce. En nuestra investigación, las glosas estaban disponibles para todas las palabras, por lo que las unidades target no destacaban y su consulta dependía de los participantes. En cualquier caso, al igual que Li (2016), encontramos que los subtítulos bilingües generan aprendizaje a largo plazo y, como en el estudio de Aldera y Mohsen (2013), observamos lo mismo con subtítulos intralingüísticos aumentados. Aunque los efectos de los dos tipos de subtítulos utilizados no difieren de manera significativa, los resultados dibujan una tendencia que apunta a que los subtítulos bilingües aumentados producirían mayores ganancias que los intralingüísticos aumentados.

El conjunto de datos expuesto nos permite evaluar tanto la efectividad del tipo de subtitulación como su incidencia sobre el aprendizaje léxico. De acuerdo a Schmitt (2010a, p. 156), las pruebas inmediatamente posteriores a un tratamiento miden la efectividad del mismo para iniciar el proceso de adquisición. En este sentido, la comparación entre medias del posttest muestra que ambos tratamientos son igual de 
efectivos, si bien las ganancias léxicas absolutas a corto plazo fueron mayores para el grupo con subtítulos bilingües aumentados. Estos resultados no confirman ni refutan los hallazgos de estudios previos, pues aunque se ha encontrado que los subtítulos bilingües generan mayor aprendizaje léxico que los subtítulos intralingüísticos tradicionales $(\mathrm{Li}, 2016)$ y que los subtítulos intralingüísticos aumentados producen mayor aprendizaje de vocabulario que los subtítulos bilingües (Sakunkoo y Sakunkoo, 2009; Kovacs y Miller, 2014), hasta ahora no se habían comparado los efectos de estas pistas cuando ambas condiciones incluyen glosas. Por otro lado, Schmitt (2010a) apunta que el verdadero aprendizaje léxico solo se puede medir a largo plazo. El contraste de las medias del pretest y el delayed posttest de cada grupo revela que, siguiendo esta definición, ambas condiciones generaron aprendizaje léxico.

Respecto al papel de las glosas en el aprendizaje, es probable que, tal como se señala en el estudio de García (2017), los participantes con acceso a subtítulos bilingües se sirvieran de la pista en la L1 para comprender el significado de las unidades léxicas desconocidas y solo una parte de ellos necesitara, o deseara, verificar el significado de estos ítems mediante las glosas, pues, existen diferencias en la manera en que cada participante se aproxima a las tareas y al input (Kormos, 2019). Esta observación puede explicar los resultados de nuestros datos, que confirman que el uso de glosas es significativamente mayor en el grupo expuesto subtítulos intralingüísticos aumentados. A pesar de ello, la consulta de las glosas por cerca de la mitad de los participantes en el grupo expuesto a subtítulos bilingües aumentados sugiere que, incluso bajo estas condiciones, los participantes prestan atención a las unidades léxicas individuales. A la vez, los porcentajes de participantes que no utilizaron las glosas en cada grupo demuestran que la disponibilidad de las ayudas en el input no garantiza su uso por parte de los aprendientes (Pujolà, 2002).

En cuanto a la relación positiva encontrada entre los conocimientos léxicos previos y el desempeño en el posttest, nuestros resultados se asemejan a los de Montero Pérez et al. (2018). Según Puimège y Peters (2019, p. 432) la correlación entre el tamaño de vocabulario y los resultados del posttest sugiere que "large differences in vocabulary size could thus account for differences in learning gains". Por ello, examinamos también la 
correlación entre los conocimientos léxicos previos y las ganancias léxicas absolutas a corto y largo plazo. La ausencia de correlación con las ganancias sugiere que el acceso al significado de las unidades habría nivelado la cobertura léxica que los participantes tenían del texto, permitiéndoles un aprovechamiento similar del tratamiento sin importar sus conocimientos léxicos previos. En otras palabras, los resultados obtenidos indican que el aumento de la cobertura léxica mediante ayudas en el input mitiga el efecto Matthew, lo que ratificaría la conveniencia de utilizar este tipo de ayudas en el input. Sin embargo, también es posible que las diferencias en los resultados de nuestros participantes en la prueba de vocabulario general no fuesen tan marcadas como para incidir en sus ganancias léxicas, por lo que sería pertinente continuar indagando sobre el tema en futuros estudios.

Sobre la exploración de la relación entre conocimiento léxico y uso de glosas, nuestros resultados muestran que los conocimientos previos no condicionan el uso de glosas y tampoco se registran diferencias significativas sobre el rendimiento en las pruebas de vocabulario en función del uso de glosas. En estudios previos, como por ejemplo en el de Montero Pérez et al. (2018), los aprendientes con mayores conocimientos léxicos previos consultaron las glosas disponibles en los subtítulos, pero en menor medida que los aprendientes con menor tamaño de vocabulario. Teng (2020), por su parte, reporta mayores ganancias para los subtítulos intralingüísticos con glosas que sin estas. Sin embargo, en estos estudios las unidades target estaban destacadas.

Nuestros datos se asemejan a lo observado en relación con el aprendizaje de vocabulario mediante la lectura, en el que tampoco se observan diferencias significativas entre usar estrategias de inferencia y consultar el diccionario (Alahmadi y Foltz, 2020). A pesar de ello, en nuestro estudio debe considerarse la ausencia medidas de qué ítems fueron consultados y cuántas veces, pues investigaciones previas con input audiovisual evidencian que mientras más se consulte una unidad, mayores son las probabilidades de aprenderla (Montero Pérez et al., 2018). También es posible que nuestros participantes no tuviesen el nivel de competencia lingüística en EL2/LE necesario para sacar el máximo provecho de las anotaciones. Algunas investigaciones 
sobre glosas en textos escritos han mostrado que los aprendientes de niveles intermedios se benefician más de estas anotaciones que los de niveles bajos (Abraham, 2008). De haber un efecto similar para el input audiovisual, se explicaría que los participantes del estudio conducido por Montero Pérez et al. (2018), al ser de nivel intermedio-alto, se beneficiaran más de las glosas que los participantes de nuestra investigación (estudiantes de una clase equivalente a un nivel A2+).

\section{CONCLUSIONES}

En este estudio hemos investigado los efectos de dos tipos de subtítulos aumentados en el aprendizaje incidental de vocabulario. Del mismo modo, hemos comparado el uso de las glosas disponibles en ambos tipos de subtítulos y analizado si tal elección del aprendiente impacta los beneficios que obtiene del tratamiento.

Los resultados evidencian que los índices de acierto de los participantes aumentan con ambos tipos de tratamiento y, aunque disminuyen al cabo de dos semanas, los efectos persisten a largo plazo. Sin embargo, el contraste de los grupos revela que tales efectos no difieren significativamente entre sí, aunque los resultados de los subtítulos bilingües aumentados son ligeramente superiores en términos de ganancias léxicas. Puede concluirse, por tanto, que los aprendientes de EL2/LE de nivel intermediobajo de nuestro estudio han obtenido ganancias léxicas a corto y a largo plazo con los dos tipos de subtítulos, por lo que pueden considerarse tratamientos efectivos que favorecen la asociación inicial entre forma y significado y generan aprendizaje receptivo a largo plazo.

Observamos asimismo que la frecuencia léxica juega un papel importante en el aprendizaje de los ítems. Los resultados para las bandas de frecuencia alta y media fueron superiores a los de la banda de baja frecuencia. Además, se aprecia mayor aumento de la media del pretest al posttest en el rango de frecuencia media, lo que podría reflejar la importancia de la atención y los conocimientos previos en el aprendizaje que produce el encuentro de las unidades en el imput audiovisual subtitulado.

Respecto al uso de glosas durante el visionado de material audiovisual con subtítulos intralingüísticos y bilingües aumentados, se ha constatado un mayor uso de glosas entre los participantes expuestos a subtítulos intralingüísticos aumentados en 
comparación con los que disponían de subtítulos bilingües aumentados. Asimismo, no se encontraron evidencias de que los conocimientos léxicos previos afectaran la decisión de los participantes de utilizar las ayudas disponibles en el input.

Los conocimientos léxicos previos tampoco mostraron incidencia en las ganancias léxicas obtenidas del tratamiento, lo que sugiere que el aumento de la cobertura léxica mediante ayudas en el imput mitiga el llamado efecto Matthew, observado en otros estudios de aprendizaje de vocabulario mediante input audiovisual (Montero et al., 2014; Peters y Webb, 2018; Peters, 2019; Suárez y Gesa, 2019). Estos resultados sugieren que el aumento de la cobertura léxica permite un aprovechamiento del input equivalente entre aprendientes con un nivel de competencia similar, al margen de los conocimientos léxicos previos que estos posean.

En cuanto a la relación entre el uso de las glosas y los beneficios obtenidos del tratamiento, no encontramos diferencias en las medias del posttest de los participantes que las consultaron y los que no lo hicieron. Sin embargo, es posible que esto se deba al tipo de instrumento de recogida de datos utilizado o al nivel de competencia lingüística en EL2/LE de los participantes. Una medida más precisa del uso de glosas nos permitiría aplicar un análisis más ajustado para indagar en esta relación.

El conjunto de resultados expuestos sugiere que el visionado de material audiovisual con subtítulos aumentados puede ser una actividad provechosa para ampliar el vocabulario en la L2/LE de manera progresiva e incidental. Además, evidencia la necesidad de continuar estudiando el tema e incidir en los procesos que tienen lugar durante el visionado y en los efectos de las características del acceso al significado que brinda cada modalidad de subtítulos con glosas.

\section{BIBLIOGRAFIA}

Abraham, L. (2008). Computer-mediated glosses in second language reading comprehension and vocabulary learning: A meta-analysis. Computer Assisted Language Learning, 21(3), pp. 199-226. https://dx.doi.org/10.1080/09588220802090246

Agustín Llach, M. D. P. (2011). Lexical Errors and Accuracy in Foreign Language Writing. Second Language Acquisition: 58. Multilingual Matters. https://doi.org/10.21832/9781847694188

Alahmadi, A. y Foltz, A. (2020) Exploring the effect of lexical inferencing and dictionary consultation on undergraduate EFL students' vocabulary acquisition. PLoS ONE, 15(7): e0236798. https://doi.org/10.1371/journal.pone.0236798 
Aldera, A. y Mohsen M. (2013). Annotations in captioned animation: Effects on vocabulary learning and listening skills. Computers \& Education, 68, pp. 60-75. https://dx.doi.org/10.1016/j.compedu.2013.04.018

American Council on the Teaching of Foreign Languages. (2012). ACTFL proficiency guidelines 2012. https://www.actfl.org/sites/default/files/pdfs/public/ACTFLProficiencyGuidelines2012_FINA L.pdf

Anderson-Inman, L., Terrazas-Arellanes, F. y Slabin, U. (2009). Supported e'Text in Captioned Videos: A Comparison of Expanded Versus Standard Captions on Student Comprehension of Educational Content. Journal of Special Education Technology, 24(3), pp. 21-34. http://dx.doi.org/10.1177/016264340902400303

Barcroft, J. (2015). Lexical Input Processing and Vocabulary Learning. Language Learning \& Language Teaching: 43. John Benjamins Publishing Company. https://doi.org/10.1075/11lt.43

Bates, D., Mächler, M., Bolker, B. y Walker, S. (2015). Fitting Linear Mixed-Effects Models Using lme4. Journal of Statistical Software, 67(1), pp. 1-48. https://doi.org/10.18637/jss.v067.i01

Cassell, W. (2018). Telenovelas, subtitulos y la adquisición del español: Los beneficios lingüisticos de mirar programas de televisión con subtitulos intralingüisticos [Estudio independiente]. Universidad de George Washington, Washington D.C., Estados Unidos de América. http://dx.doi.org/10.13140/RG.2.2.34139.82727

Chacón-Beltrán, R.;AAbello-Contesse, C. y Torreblanca-López, M.a del M. (2010). Vocabulary Teaching and Learning: Introduction and Overview. En R. Chacón-Beltrán, C. Abello-Contesse y M. del M. Torreblanca-López (Eds.), Insights Into Non-native Vocabulary Teaching and Learning. Second Language Acquisition: 52, pp. 1-12. Multilingual Matters. https://doi.org/10.21832/9781847692900-002

Chang, S. (2003). The interaction between schemata and subtitles. Journal of National Taipei University of Technology, 39(1), pp. 209-228. http:/ / citeseerx.ist.psu.edu/viewdoc/download?doi=10.1.1.531.7273\&rep=rep1\&type=pdf

Cintrón-Valentín, M., García-Amaya, L. y Ellis, N. (2019). Captioning and grammar learning in the L2 Spanish classroom. The language learning journal, 47(4), pp. 439-459. https://doi.org/10.1080/09571736.2019.1615978

Cokely, M. y Muñoz, C. (2019). Captioned Video, Vocabulary and Visual Prompts: An Exploratory Study. En C. Herrero e I. Vanderschelden (Eds.), Using Film and Media in the Language Classroom: Reflections on Research-led Teaching. New Perspectives on Language and Education, 73, pp. 61-75. Multilingual Matters. https://doi.org/10.21832/9781788924498-008

Davies, M. Banco de datos [en línea]. Corpus del Español: Word and Phrase. https://www.wordandphrase.info/span/ [07 de abril de 2019]

Echeverría, M., Herrera, M. y Segure, J. (2005). TEVI-R test de vocabulario en imágenes: manual de aplicación (3. ${ }^{a}$ ed.). Editorial Universidad De Concepcion. https://doi.org/10.4067/S0718-04622004049000010

García, B. (2017). Bilingual Subtitles for Second-Language Acquisition and Application to Engineering Education as Learning Pills. Computer Applications in Engineering Education, 25, pp. 468-479. https://doi.org/10.1002/cae.21814

Hidalgo, M. (2020). Efectos del método de presentación léxica en la recuperación y el reconocimiento del vocabulario en español LE/L2 para italófonos. RILEX. Revista sobre investigaciones léxicas, 3(I), pp. 4773. https://doi.org/10.17561/rilex.3.1.5377 
Horst, M., Cobb, T. y Meara, P. (1998). Beyond a Clockwork Orange: Acquiring second language vocabulary through reading. Reading in a Foreign Language, 11(2), pp. 207-223. https://nflrc.hawaii.edu/rfl/PastIssues/rfl112horst.pdf

Hsieh, Y. (2019). Effects of video captioning on EFL vocabulary learning and listening comprehension. Computer Assisted Language Learning, 33, pp. 567-589. https://doi.org/10.1080/09588221.2019.1577898

Hsu, H.-T. (2018). Incidental professional vocabulary acquisition of EFL business learners: Effect of captioned video with glosses. The JALT CALL Journal, 14(2), pp. 119-142. https://doi.org/10.29140/jaltcall.v14n2.227

Kormos, J. (2019). How Does Vocabulary Fit Into Theories of Second Language Learning? En S. Webb (Ed.), The Routledge Handbook of Vocabulary Studies. pp.207-222. [Edición para Kindle]. Taylor and Francis. https://doi.org/10.4324/9780429291586-14

Kovacs, G. y Miller, R. (2014). Smart Subtitles for Vocabulary Learning. CHI '14: Proceedings of the SIGCHI Conference on Human Factors in Computing Systems, pp. 853-862. https://doi.org/10.1145/2556288.2557256

Kremmel, B. (2019). Measuring Vocabulary Learning Progress. En S. Webb (Ed.), The Routledge Handbook of Vocabulary Studies, pp. 406-418 [Edición para Kindle]. Taylor and Francis. https://doi.org/10.4324/9780429291586-26

Laufer, B. y Goldstein, Z. (2004). Testing vocabulary knowledge: size, strength, and computer adaptiveness. Language Learning, 54(3), pp. 399-436. https://doi.org/10.1111/j.0023-8333.2004.00260.x

Laufer, B. (2005). Focus on Form in Second Language Vocabulary Learning. EUROSL A Yearbook, 5(1), pp. 223-250. John Benjamins Publishing Company. https://doi.org/10.1075/eurosla.5.11lau

Lazareva, E. y Loerts, H. (2017). Double subtitles as an effective tool for vocabulary learning. Konin Language Studies, 5(1), pp. 61-92. https://www.rug.nl/research/portal/files/51307196/KSJ 5161 92.pdf

Lenth, R. (2018). emmeans: Estimated Marginal Means, aka Least-Squares Means. https://CRAN.Rproject.org/package $=$ emmeans.

Li, M. (2016). An Investigation into the Differential Effects of Subtitles (First Language, Second Language, and Bilingual) on Second Language Vocabulary Acquisition [Tesis doctoral]. Universidad de Edimburgo, Edimburgo, Escocia. https:/ / era.ed.ac.uk/bitstream/handle/1842/22013/Li2016.pdf?sequence=2\&isAllowed =y

Liao, S., Kruger, J. L. y Doherty, S. (2020). The impact of monolingual and bilingual subtitles on visual attention, cognitive load, and comprehension. The Journal of Specialised Translation, 33, pp. 70-98.

Lindgren, E. y Muñoz, C. (2013). The influence of exposure, parents, and linguistic distance on young European learners' foreign language comprehension. International Journal of Multilingualism, 10(1), pp. 105-129. https://doi.org/10.1080/14790718.2012.679275

Ma, Q. (2013). Computer Assisted Vocabulary Learning: Framework and Tracking User Data. CALICO Journal, 30, pp. 230-243. https://www.jstor.org/stable/calicojournal.30.230

Marian, V., Blumenfeld, H. y Kaushanskaya, M. (2007). The Language Experience and Proficiency Questionnaire (LEAP-Q): Assessing Language Profiles in Bilinguals and Multilinguals. Journal of Speech, Language, and Hearing Research, 50(4), pp. 940-967. https://doi.org/10.1044/1092$\underline{4388(2007 / 067)}$ 
Martínez Baztán, A. (2008). La evaluación oral: una equivalencia entre las guidelines de ACTFL y algunas escalas del MCER. Editorial de la Universidad de Granada. https:/ / digibug.ugr.es/bitstream/handle/10481/1877/17457853.pdf?sequence=1\&isAllowed=y

Mitterer, H. y McQueen, J.M. (2009). Foreign Subtitles Help but Native-Language Subtitles Harm Foreign Speech Perception. PLOS ONE, 4(11), pp. 1-5. https://doi.org/10.1371/journal.pone.0007785

Mohsen, M. y Balakumar, M. (2011). A review of multimedia glosses and their effects on L2 vocabulary acquisition in CALL literature. ReCALL 23(2), pp. 135-159. https://doi.org/10.1017/S095834401100005X

Montero Pérez, M., Peters, E., Clarebout, G. y Desmet, P. (2014). Effects of captioning on video comprehension and incidental vocabulary learning. Language Learning \& Technology, 18(1), pp. 118141.

Montero Pérez, M., Peters, E. y Desmet, P. (2018). Vocabulary learning through viewing video: the effect of two enhancement techniques. Computer Assisted Language Learning, 31(1-2), pp. 1-26. https://doi.org/10.1080/09588221.2017.1375960

Montero Pérez, M. (2019). Pre-learning vocabulary before viewing captioned video: an eye-tracking study. The Language Learning Journal, 47(4), pp. 460-478. https://doi.org/10.1080/09571736.2019.1638623

Montero Pérez, M. y Rodgers, M. (2019). Video and language learning [Editorial]. The L anguage Learning Journal, 47(4), pp. 403-406. https://doi.org/10.1080/09571736.2019.1629099

Muñoz-Basols, J. (2019). Going beyond the comfort zone: multilingualism, translation and mediation to foster plurilingual competence. Language, Culture and Curriculum, 32(3), pp. 299-321. https://doi.org/10.1080/07908318.2019.1661687

Nation, P. (2001). Cambridge applied linguistics series. Learning vocabulary in another language. Cambridge University Press.

Nation, P. y Chung, T. (2011). Teaching and testing vocabulary. En M. Long y C. Doughty (Eds.), The handbook of language teaching, pp. 543-559. Wiley-Blackwell. https://doi.org/10.1002/9781444315783.ch28

Nation, P. (2019). The Different Aspects of Vocabulary Knowledge. En S. Webb (Ed.), The Routledge Handbook of Vocabulary Studies, pp.15-29 [Edición para Kindle]. Taylor and Francis. https://doi.org/10.4324/9780429291586-2

Neuman, S. y Koskinen, P. (1992). Captioned Television as Comprehensible Input: Effects of Incidental Word Learning from Context for Language Minority Students. Reading Research Quarterly, 27(1), pp. 94-106. https://doi.org/10.2307/747835

Pavičić, V. (2008). Vocabulary Learning Strategies and Foreign Language Acquisition. Second Language Acquisition: 27. Multilingual Matters. https://doi.org/10.21832/9781847690401

Peters, E., Heynen, E. y Puimège, E. (2016). Learning vocabulary through audiovisual input: The differential effect of L1 subtitles and captions. System, 63, pp. 134-148. https://doi.org/10.1016/i.system.2016.10.002

Peters, E. (2018). The effect of out-of-class exposure to English language media on learners' vocabulary knowledge. International Journal of Applied Linguistics, 169(1), pp. 142-168. https://doi.org/10.1075/itl.00010.pet 
Peters, E. y Webb, S. (2018). Incidental vocabulary acquisition through viewing L2 television and factors that affect learning. Studies in Second Language Acquisition, 40(3), pp. 551-577. https://doi.org/10.1017/S0272263117000407

Peters, E. (2019). The Learning of Single-Word Items. En S. Webb (Ed.), The Routledge Handbook of V ocabulary Studies, pp. 125-142 [Edición para Kindle]. Taylor and Francis. https://doi.org/10.4324/9780429291586-9

Puimège, E. y Peters, E. (2019). Learning L2 vocabulary from audiovisual input: an exploratory study into incidental learning of single words and formulaic sequences. The Language Learning Journal, 47(4), pp. 424-438. https://doi.org/10.1080/09571736.2019.1638630

Pujadas, G. y Muñoz, C. (2019). Extensive viewing of captioned and subtitled TV series: a study of L2 vocabulary learning by adolescents. The Language Learning Journal, 47(4), pp. 479-496. https://doi.org/10.1080/09571736.2019.1616806

Pujadas, G. y Muñoz, C. (2020). Examining adolescent EFL learners' tv viewing comprehension through captions and subtitles. Studies in Second Language Acquisition, 42(3), pp. 551-575. https://doi.org/10.1017/S0272263120000042

Pujolà, J.-T. (2002). CALLing for help: researching language learning strategies using help facilities in a webbased multimedia program. ReCALL 14(2), pp. 235-262. https://doi.org/10.1017/S0958344002000423

Raine, P. (2012). Incidental learning of vocabulary through subtitled authentic videos [Trabajo de grado de maestría]. Universidad de Birmingham, Birmingham, Reino Unido. https://www.birmingham.ac.uk/Documents/collegeartslaw/cels/essays/matefltesldissertations/RAINE619605DISS.pdf

Read, J. (2019). Key Issues in Measuring Vocabulary Knowledge. En S. Webb (Ed.), The Routledge Handbook of Vocabulary Studies, pp. 545-560 [Edición para Kindle]. Taylor and Francis. https://doi.org/10.4324/9780429291586-34

RStudio Team. (2015). RStudio (versión 3.5.2) [Software de computación]. http://www.rstudio.com/

Sakunkoo, N. y Sakunkoo, P. (2009). GliFlix: Using Movie Subtitles for Language Learning. UIST, ACM Symposium on User Interface Software and Technology. https://uist.acm.org/archive/adjunct/2009/pdf/demos/paper171.pdf

Schmitt, N. (2008). Instructed second language vocabulary learning. Language Teaching Research, 12(3), pp. 329363. https://doi.org/10.1177/1362168808089921

Schmitt, N. (2010a). Reasearch and Practice in Applied Linguistics. Researching vocabulary: A vocabulary reasearch manual. Palgrave Macmillan.

Schmitt, N. (2010b). Key Issues in Teaching and Learning Vocabulary. En R. Chacón-Beltrán, C. AbelloContesse y M. ${ }^{a}$ del M. Torreblanca-López (Eds.), Insights Into Non-native Vocabulary Teaching and Learning. Second Language Acquisition: 52, pp. 28-40. Multilingual Matters. https://doi.org/10.21832/9781847692900-004

Stewart, M. y Pertusa, I. (2004). Gains to Language Learners from Viewing Target Language ClosedCaptioned Films. Foreign Language Annals, 37(3), pp. 438-442. https://doi.org/10.1111/j.19449720.2004.tb02701.x 
Suárez, M. y Gesa, F. (2019). Learning vocabulary with the support of sustained exposure to captioned video: do proficiency and aptitude make a difference? The Language Learning Journal, 47(4), pp. 497-517. https://doi.org/10.1080/09571736.2019.1617768

Talaván Zanón, N. (2011). La influencia efectiva de los subtítulos en el aprendizaje de lenguas extranjeras: análisis de investigaciones previas. SENDEBAR: Revista de la Facultad de Traducción e Interpretación de la Universidad de Granada, 22, 265-282. http://revistaseug.ugr.es/index.php/sendebar\%20/article/download/354/386

Teng, F. (2020). Vocabulary learning through videos: captions, advance-organizer strategy, and their combination. Computer Assisted Language Learning. https:/ / doi.org/10.1080/09588221.2020.1720253

van Buuren, S. y Groothuis-Oudshoorn, K. (2011). mice: Multivariate Imputation by Chained Equations in R. Journal of Statistical Software, 45(3), pp. 1-67. https://doi.org/10.18637/jss.v045.i03

Vanderplank, R. (2016). Captioned Media in Foreign Language Learning and Teacbing: Subtitles for the Deaf and Hardof-Hearing as Tools for Language Learning. Palgrave Macmillan. https://doi.org/10.1057/978-1-137$\underline{50045-8}$

Wang, Y. (2019). Effects of L1/L2 Captioned TV Programs on Students' Vocabulary Learning and Comprehension. Calico Journal, 36(3), pp. 204-224. https://doi.org/10.1558/cj.36268

Webb, S. y Rodgers, M. (2009). Vocabulary Demands of Television Programs. Language Learning, 59(2), pp. 335-366. https://doi.org/10.1111/j.1467-9922.2009.00509.x

Webb, S. (2010a). A corpus driven study of the potential for vocabulary learning through watching movies. International Journal of Corpus Linguistics, 15(4), pp. 497-519. https://doi.org/10.1075/ijcl.15.4.03web

Webb, S. (2010b). Using glossaries to increase the lexical coverage of television programs. Reading in a Foreign Language, 22(1), pp. 201-221. https://pdfs.semanticscholar.org/f2a0/89cfacf3bf202f5728b3bf1c8bcc215c0607.pdf

Webb, S. y Chang, A. C.-S. (2015). Second language vocabulary learning through extensive reading with audio support: How do frequency and distribution of occurrence affect learning? Language Teaching Research, 19(6), pp. 667-686. https://doi.org/10.1177/1362168814559800

Webb, S. (2016). Learning vocabulary through meaning-focused input: Replication of Elley (1989) and Liu \& Nation (1985). Language Teaching, 49(1), pp. 129-140. https://doi.org/10.1017/S0261444815000051

Webb, S. (2019). Incidental vocabulary learning. En S. Webb (Ed.), The Routledge Handbook of Vocabulary Studies, pp. 225-239 [Edición para Kindle]. Taylor and Francis. https://doi.org/10.4324/9780429291586$\underline{15}$

Winke, P., Gass, S. y Sydorenko, T. (2010). The effects of captioning videos used for foreign language listening activities. Language Learning \& Technology, 14(1), pp. 65-86. https://scholarspace.manoa.hawaii.edu/bitstream/10125/44203/1/14 01 winkegasssydorenko. pdf 


\section{ANEXO}

Unidades léxicas target de la prueba definitiva

\begin{tabular}{|c|c|c|}
\hline Unidad léxica & Categoría gramatical & $\begin{array}{c}\text { Frecuencia en el Corpus del } \\
\text { Español (al } 7 / 04 / 2019)\end{array}$ \\
\hline encargar & verbo & 1293 \\
\hline cuadro & sustantivo & 1467 \\
\hline sede & sustantivo & 1713 \\
\hline devolver & verbo & 1782 \\
\hline ruido & sustantivo & 2174 \\
\hline pesado & adjetivo & 2261 \\
\hline huir & verbo & 2447 \\
\hline aviso & sustantivo & 2685 \\
\hline huella & sustantivo & 2808 \\
\hline humo & sustantivo & 3316 \\
\hline oler & verbo & 3649 \\
\hline casualidad & sustantivo & 3780 \\
\hline despacho & sustantivo & 3947 \\
\hline aliento & sustantivo & 3950 \\
\hline disculpar & verbo & 4010 \\
\hline prisa & sustantivo & 4321 \\
\hline embajada & sustantivo & 4325 \\
\hline recibo & sustantivo & 4712 \\
\hline lío & sustantivo & 5247 \\
\hline viuda & sustantivo & 6354 \\
\hline bombardear & verbo & 6715 \\
\hline patrulla & sustantivo & 7138 \\
\hline sótano & sustantivo & 8333 \\
\hline construido & adjetivo & 8804 \\
\hline nuca & sustantivo & 9195 \\
\hline tejado & sustantivo & 9343 \\
\hline encantado & adjetivo & 9890 \\
\hline forzosamente & adverbio & 11255 \\
\hline valija & sustantivo & 13799 \\
\hline fantasmal & adjetivo & 15788 \\
\hline antiaéreo & adjetivo & 16463 \\
\hline garabato & sustantivo & 16916 \\
\hline bisonte & sustantivo & 23834 \\
\hline apestado & adjetivo & 29988 \\
\hline traspapelar & verbo & 34727 \\
\hline
\end{tabular}

